\title{
Surface Targeting of the Dopamine Transporter Involves Discrete Epitopes in the Distal C Terminus But Does Not Require Canonical PDZ Domain Interactions
}

\author{
Christian Bjerggaard, ${ }^{1}$ Jacob U. Fog, ${ }^{1}$ Hanne Hastrup, ${ }^{2}$ Kenneth Madsen, ${ }^{1}$ Claus J. Loland, ${ }^{1}$ Jonathan A. Javitch, ${ }^{2}$ and \\ Ulrik Gether ${ }^{1}$ \\ ${ }^{1}$ Molecular Neuropharmacology Group, Department of Pharmacology, The Panum Institute, University of Copenhagen, DK-2200 Copenhagen, Denmark, \\ and ${ }^{2}$ Center for Molecular Recognition and the Departments of Psychiatry and Pharmacology, Columbia University College of Physicians and Surgeons, \\ New York, New York 10032
}

The human dopamine transporter (hDAT) contains a C-terminal type 2 PDZ (postsynaptic density 95/Discs large/zona occludens 1) domain-binding motif (LKV) known to interact with PDZ domain proteins such as PICK1 (protein interacting with C-kinase 1). As reported previously, we found that, after deletion of this motif, hDAT was retained in the endoplasmic reticulum (ER) of human embryonic kidney (HEK) 293 and Neuro2A cells, suggesting that PDZ domain interactions might be critical for hDAT targeting. Nonetheless, substitution of LKV with SLL, the type 1 PDZ-binding sequence from the $\beta_{2}$-adrenergic receptor, did not disrupt plasma membrane targeting. Moreover, the addition of an alanine to the hDAT C terminus ( + Ala), resulting in an LKVA termination sequence, or substitution of LKV with alanines (3xAla_618-620) prevented neither plasma membrane targeting nor targeting into sprouting neurites of differentiated N2A cells. The inability of + Ala and 3xAla_618-620 to bind PDZ domains was confirmed by lack of colocalization with PICK1 in cotransfected HEK293 cells and by the inability of corresponding C-terminal fusion proteins to pull down purified PICK1. Thus, although residues in the hDAT C terminus are indispensable for proper targeting, PDZ domain interactions are not required. By progressive substitutions with $\beta_{2}$-adrenergic receptor sequence, and by triple-alanine substitutions in the hDAT C terminus, we examined the importance of epitopes preceding the LKV motif. Substitution of $\mathrm{RHW}_{615-617}$ with alanines caused retention of the transporter in the ER despite preserved ability of this mutant to bind PICK1. We propose dual roles of the hDAT C terminus: a role independent of PDZ interactions for ER export and surface targeting, and a not fully clarified role involving PDZ interactions with proteins such as PICK1.

Key words: targeting; trafficking; ER export; neurotransmitter transporters; PDZ domains; oligomerization

\section{Introduction}

The dopamine transporter (DAT) is a presynaptic membrane protein of dopaminergic nerve terminals that terminates dopamine signaling by rapidly sequestering released dopamine from the synaptic cleft (Amara and Kuhar, 1993; Norregaard and Gether, 2001). The transporter has received much attention because it is the principle target for the action of widely abused psychostimulants, such as cocaine and amphetamine (Chen and Reith, 2000; Norregaard and Gether, 2001). The DAT is a member of the class of $\mathrm{Na}^{+} / \mathrm{Cl}^{-}$-dependent transporters along with several other neurotransmitter transporters, such as the norepi-

Received Nov. 13, 2003; revised June 23, 2004; accepted June 23, 2004

This work was supported in part by National Institute of Health Grants P01 DA 12408 (U.G., J.A.J.) and DA 11495 and MH 57324 (J.A.J.), the Lundbeck Foundation (U.G.), the Novo Nordic Foundation (U.G.), and the Lebovitz Trust (J.A.J.). J.U.F. was supported by a fellowship from H. Lundbeck A/S (Valby, Denmark) and the Medicon Valley Academy (Copenhagen, Denmark). We thank Dr. Harald Sitte for helpful suggestions on this manuscript. We also thank Lisbeth Delorang Andersen for technical assistance.

Correspondence should be addressed to Dr. Ulrik Gether, Molecular Neuropharmacology Group, Department of Pharmacology, The Panum Institute, University of Copenhagen, DK-2200 Copenhagen N, Denmark. E-mail: gether@neuropharm.ku.dk.

DOI:10.1523/JNEUROSCI.1863-04.2004

Copyright $\odot 2004$ Society for Neuroscience $\quad 0270-6474 / 04 / 247024-13 \$ 15.00 / 0$ nephrine (NET), serotonin, GABA, and glycine transporters (Chen and Reith, 2000; Norregaard and Gether, 2001).

Both the activity and the surface availability of the DAT is believed to be tightly regulated by different cellular mechanisms, the best characterized being modulation by protein kinase $\mathrm{C}$ (PKC) activation (for review, see Blakely and Bauman, 2000; Zahniser and Doolen, 2001; Robinson, 2002). Activation of this kinase causes an acute reduction in DAT transport activity because of clathrin-dependent redistribution of the transporter from the cell surface to an intracellular compartment (Daniels and Amara, 1999; Granas et al., 2003) followed by recycling of the DAT back to the cell surface (Loder and Melikian, 2003) or alternatively targeting to lysosomal degradation (Daniels and Amara, 1999). The retention of proteins in the endoplasmic reticulum (ER) is believed to fulfill an important quality-control mechanism, and, accordingly, it is conceivable that the export of DAT from the ER and its subsequent targeting to the cell surface are also tightly regulated processes (Ellgaard et al., 1999; Ellgaard and Helenius, 2003). It is interesting, therefore, that various truncations of the DAT C terminus (Torres et al., 2003), as well as of the C terminus of the highly homologous NET (Bauman and Blakely, 2002), impair surface targeting and result in retention of the 
transporter inside the cell. This supports a hypothesis in which proper ER export, maturation, and membrane insertion require specific protein-protein interactions between the $\mathrm{C}$ terminus and specific intracellular proteins. Interestingly, the DAT possesses a PDZ (postsynaptic density 95/Discs large/zona occludens 1) domain-binding sequence at its extreme $\mathrm{C}$ terminus that was shown recently to interact with the PDZ domain-containing protein PICK1 (protein interacting with C-kinase 1) (Torres et al., 2001). This led to the inference that PDZ domain interactions are critical for ER export and surface targeting of the DAT (Torres et al., 2001). Importantly, a similar role of PDZ domain interactions in these events has been suggested previously for other membrane-associated proteins, such as the growth factor proTGF- $\alpha$ (Fernandez-Larrea et al., 1999), the NMDA receptor NR1 subunit (Standley et al., 2000), and the GABA transporters (Muth et al., 1998; Perego et al., 1999).

Here we investigated the role of the human DAT (hDAT) C terminus for proper maturation and plasma membrane targeting. Our data demonstrate that, although the extreme $\mathrm{C}$ terminus is indispensable for directing the transporter to the cell surface, canonical PDZ domain interactions are not required. We identify mutants that are efficiently inserted into the plasma membrane and targeted to neuronal processes but are incapable of forming PDZ domain interactions, as well as mutants that are retained in the ER but capable of binding to the PICK1 PDZ domain. We suggest a model in which the extreme $\mathrm{C}$ terminus of DAT might serve dual roles: a role independent of PDZ domain interactions in the ER export and surface targeting pathway, and a subsequent not fully clarified regulatory role involving PDZ domain interactions with scaffolding proteins, such as PICK1.

\section{Materials and Methods}

Site-directed mutagenesis. We used a synthetic hDAT (synDAT) gene tagged at the $\mathrm{N}$ terminus with a FLAG epitope (Asp-Tyr-Lys-Asp-AspAsp-Asp-Lys). The nucleotide sequence of this construct and its generation will be described in future studies (L. Shi and J. A. Javitch, unpublished observations). This gene was inserted into the bicistronic mammalian expression vector pCIHygro (Rees et al., 1996; Saunders et al., 2000). The mutant transporters were constructed by two-step PCR mutagenesis using Pfu polymerase (Stratagene, La Jolla, CA) and pCIHygro-FLAG-synDAT as template. The mutant PCR fragments were digested with the appropriate enzymes, purified by agarose gel electrophoresis, and cloned into pCIHygro-FLAG-synDAT. All mutants were verified by restriction enzyme mapping and sequenced using the $\mathrm{ABI}$ Prism BigDye Terminator Cycle Sequencing Ready Reaction kit (Applied Biosystems, Foster City, CA) on an ABI310 automated sequencer (Applied Biosystems).

Cell culture. Human embryonic kidney (HEK) 293 and mouse Neuro2A (N2A) cells were grown in DMEM medium with Glutamax (L-alanyl-L-glutamine), $10 \%$ fetal calf serum, and $0.01 \mathrm{mg} / \mathrm{ml}$ gentamicin (all reagents from Invitrogen, Carlsbad, CA) at $37^{\circ} \mathrm{C}$ in a humidified $5 \%$ $\mathrm{CO}_{2}$ atmosphere.

Transfection. HEK293 or N2A cells were transfected using either Lipofectamine or Lipofectamine 2000 reagent (Invitrogen). When using Lipofectamine reagent for transient expression, the cells were seeded the day before transfection in a $75 \mathrm{~cm}^{2}$ flask coated with $10 \mathrm{mg} / \mathrm{ml}$ poly-Dlysine (Sigma, St. Louis, MO) in PBS buffer. The cells were seeded at a density of $3.5 \times 10^{6}$ cells per $75 \mathrm{~cm}^{2}$ flask to obtain a cell density of $50-80 \%$ at the day of transfection. Transfection was performed according to the protocol of the manufacturer using $3 \mu \mathrm{g}$ of DNA and $7 \mu \mathrm{g}$ of DNA per $75 \mathrm{~cm}^{2}$ flask of HEK293 and N2A cells, respectively. The DNA and Lipofectamine were mixed 1:3, and the mixture was incubated with the cells for $5 \mathrm{hr}$ in the cell incubator. For stable expression using Lipofectamine reagent, HEK293 cells were seeded in $100 \mathrm{~mm}$ tissue culture plates, grown to $\sim 30 \%$ confluence, and subsequently transfected with 2 $\mu \mathrm{g}$ of the pCIHygro constructs. A stably transfected pool was selected with $200 \mu \mathrm{g} / \mathrm{ml}$ hygromycin (Invitrogen) starting $2 \mathrm{~d}$ after transfection and continuing until control cells were dead, after which selection pressure was maintained with $100 \mu \mathrm{g} / \mathrm{ml}$ hygromycin. For transient transfection of cells used for immunofluorescence, the HEK293 or N2A cells $(2 \times$ $10^{6}$ cells) were seeded in a $25 \mathrm{~cm}^{2}$ flask coated with $10 \mathrm{mg} / \mathrm{ml}$ poly-Dlysine (Sigma) in PBS buffer. The cells were transfected the day after seeding with $5 \mu \mathrm{g}$ of DNA/ $15 \mu$ l of Lipofectamine 2000 reagent according to the instructions of the manufacturer. For transient transfection of cells used for preparation of crude membranes, $9 \times 10^{6}$ HEK293 cells were seeded in $175 \mathrm{~cm}^{2}$ flasks and the following day were transfected with $6 \mu \mathrm{g}$ of DNA/18 $\mu \mathrm{l}$ of Lipofectamine 2000 reagent. For double transfection with DAT mutants and EGFP (enhanced green fluorescent protein)PICK1, HEK293 cells were transfected with $2 \mu \mathrm{g}$ of pCIHygro DAT construct and $2 \mu \mathrm{g}$ of pEGFP-C2 rPICK1 (a kind gift from Dr. Kumlesh Dev, Novartis Pharma, Basel, Switzerland). A stably transfected pool was selected with $200 \mu \mathrm{g} / \mathrm{ml}$ hygromycin (Invitrogen) and $200 \mu \mathrm{g} / \mathrm{ml} \mathrm{G} 418$ starting $2 \mathrm{~d}$ after transfection and continuing until control cells were dead.

$\left[{ }^{3} \mathrm{H}\right]$ dopamine uptake experiments. Uptake assays were performed using 2,5,6- $\left({ }^{3} \mathrm{H}\right)$-dopamine (7-21 Ci/mmol) (Amersham Biosciences, Little Chalfont, UK). The $\left[{ }^{3} \mathrm{H}\right]$ dopamine uptake assay was performed on whole cells $3 \mathrm{~d}$ after transfection (Granas et al., 2003). On the day after transfection, the cells were seeded at a density of $1 \times 10^{5}$ cells per well in 24 -well plates coated with $20 \mathrm{mg} / \mathrm{ml}$ poly-D-lysine (Sigma) in PBS buffer. Alternatively, cells were seeded in a 12-well plate (coated as above) at a density of $3 \times 10^{5}$ cells per well. After seeding, the cells were left for $2 \mathrm{~d}$ in the incubator. Before the experiment, the cells were washed once in 500 $\mu l$ of uptake buffer [ $25 \mathrm{~mm}$ HEPES, pH 7.4, with $130 \mathrm{~mm} \mathrm{NaCl}, 5.4 \mathrm{~mm}$ $\mathrm{KCl}, 1.2 \mathrm{mM} \mathrm{CaCl}_{2}, 1.2 \mathrm{mM} \mathrm{MgSO}_{4}, 1 \mathrm{~mm}$ L-ascorbic acid, $5 \mathrm{~mm}$ D-glucose, and $1 \mu \mathrm{M}$ of the catechol-O-methyltransferase inhibitor Ro 41-0960; (Sigma)]. Next, $400 \mu \mathrm{l}$ of prewarmed uptake buffer plus $50 \mu \mathrm{l}$ of nonlabeled dopamine (Research Biochemicals, Natick, MA) (final assay concentrations ranged from $10 \mathrm{~nm}$ to $1 \mathrm{~mm}$ ) were added. Uptake was initiated by addition of $\sim 90 \mathrm{~nm}\left[{ }^{3} \mathrm{H}\right]$ dopamine in $50 \mu$ lof uptake buffer. After 10 min of incubation at $37^{\circ} \mathrm{C}$, the cells were washed twice with 500 $\mu \mathrm{l}$ of ice-cold uptake buffer, lysed in $300 \mu \mathrm{l}$ of $1 \%$ SDS, and left for $1 \mathrm{hr}$ at $37^{\circ} \mathrm{C}$. All samples were subsequently transferred to 24 -well counting plates (NEN, Boston, MA), followed by the addition of $600 \mu \mathrm{l}$ of Optiphase HiSafe 3 scintillation fluid (NEN). The samples were counted in a Wallac Tri-Lux $\beta$-scintillation counter (NEN). All determinations were performed in triplicate.

Western blot and surface biotinylation. Two days before the experiment, $7 \times 10^{6}$ stably transfected HEK293 cells were seeded in $100 \mathrm{~mm}$ tissue culture dishes (Corning, Corning, NY) coated with $20 \mathrm{mg} / \mathrm{ml}$ poly-Dlysine (Sigma) in PBS. On the day of the experiment, the cells were washed twice with PBS buffer and incubated with freshly made $1.5 \mathrm{mg} / \mathrm{ml}$ sulfosuccinimidyl-2-(biotinamido)ethyl-1,3-dithiopropionate (sulfoNHS-SS-biotin) (Pierce, Rockford, IL) in cold PBS for $40 \mathrm{~min}$ at $4^{\circ} \mathrm{C}$, followed by $20 \mathrm{~min}$ incubation in cold $100 \mathrm{~mm}$ glycine $\left(4^{\circ} \mathrm{C}\right)$. The cells were lysed in lysis buffer $[25 \mathrm{~mm}$ Tris, $\mathrm{pH}$ 7.5, containing $1 \mathrm{~mm}$ EDTA, 5 mM $N$-ethylmaleimide (NEM) (Sigma), $200 \mu \mathrm{M}$ PMSF (Sigma), and a protease inhibitor mixture tablet (Roche Products, Hertfordshire, UK)], harvested, and centrifuged at $1,000 \times g$ for $5 \mathrm{~min}$. The cell pellets were resuspended in $1 \mathrm{ml}$ of solubilization buffer (lysis buffer supplemented with $150 \mathrm{~mm} \mathrm{NaCl}$ and $1.0 \%$ Triton $\mathrm{X}-100$ ) and left for 30 min at $4^{\circ} \mathrm{C}$ with constant shaking. Lysates were centrifuged at 20,000 $\times g$ for $30 \mathrm{~min}$ at $4^{\circ} \mathrm{C}$, and the protein concentration in the supernatants was determined using a Bio-Rad (Hercules, CA) DC Protein Assay kit. Monomeric avidin beads ( $175 \mu \mathrm{l}$; Pierce) were added to the samples (500 $\mu \mathrm{g}$ of solubilized protein) and incubated for $1 \mathrm{hr}$ at room temperature. The beads were washed four times with solubilization buffer, before elution with $50 \mu$ l of $2 \times$ loading buffer [ $100 \mathrm{~mm}$ Tris- $\mathrm{HCl}, \mathrm{pH} 6.8,20 \%$ glycerol, $10 \%$ SDS, $0.1 \mathrm{~m}$ dithiothreitol (DTT), and $0.2 \%$ bromophenol blue] for $30 \mathrm{~min}$ at room temperature. The eluate was separated by $10 \%$ SDSPAGE, transferred to a nitrocellulose membrane, and blotted with the primary M2 anti-FLAG antibody (1:400; Sigma) and secondary horseradish peroxidase-coupled goat anti-mouse antibody (1:20,000; Pierce) in blocking solution [Tris-buffered saline (TBS) buffer with 5\% Carna- 
tion dry milk and $0.05 \%$ Tween 20 ], and the protein was visualized with SuperSignal (Pierce) according to the protocol of the manufacturer.

Immunofluorescence. HEK293 and N2A cells transiently transfected using Lipofectamine 2000 reagent were seeded the day after transfection on coverslips coated with poly-D-lysine (Sigma) in PBS buffer. Differentiation of the N2A cells was achieved by the addition of $2 \mathrm{~mm}$ dibutyrylcAMP (Sigma) to the cell media the day after transfection as the cells were seeded on coverslips, and, $2 \mathrm{~d}$ after seeding, the cells were fixed in ice-cold methanol, blocked in blocking solution [ $5 \%$ goat serum and $1 \%$ bovine serum albumin (BSA) in PBS buffer], incubated with primary antibody (M2 anti-FLAG 1:200; Sigma) and rabbit anti-calnexin 1:300 (Stressgen, San Diego, CA) and secondary antibody (goat anti-mouse Alexa Fluor 488 and goat anti-rabbit Alexa Fluor 568; Molecular Probes, Eugene, OR). HEK293 cells stably transfected with both EGFP-PICK1 and DAT mutants were seeded on poly-D-lysine (Sigma) coated coverslips, fixed the following day in $4 \%$ formaldehyde solution in PBS at room temperature for $20 \mathrm{~min}$, blocked with blocking-permeabilizing solution (5\% goat serum, $1 \%$ BSA, and $0.1 \%$ Triton X-100 in PBS buffer) for $45 \mathrm{~min}$, and incubated with primary antibody (MAB369 anti-DAT antibody, 1:1000; Chemicon, Temecula, CA) for $1 \mathrm{hr}$ and secondary antibody (goat anti-rat Alexa Fluor 568; Molecular Probes) for $1 \mathrm{hr}$. Stained cells were visualized using a Zeiss (Oberkochen, Germany) LSM 510 confocal laserscanning microscope with an oil immersion $63 \times$ objective. The Alexa Fluor 488 and EGFP was excited with the $488 \mathrm{~nm}$ laser line from an argon-krypton laser and the emitted light was detected using a 505-550 $\mathrm{nm}$ bandpass filter, whereas the Alexa Fluor 568 was excited at $543 \mathrm{~nm}$ with a HeNe laser and the emitted light was detected using a $585 \mathrm{~nm}$ long-pass filter. The two fluorophores were detected separately, and the resulting images were combined using the Adobe Photoshop 6.0 software (Adobe Systems, San Jose, CA).

Proteasome $26 S$ inhibition assay. HEK293 cells stably transfected with wild-type (WT) or $\triangle \mathrm{LKV}$ DAT were seeded in poly-D-lysine-coated 60 $\mathrm{mm}$ dishes. On the day of the experiment, $20 \mu \mathrm{M}$ MG132 (Sigma) was added to the cell media, the cells were incubated for $0,3,6$, or $9 \mathrm{hr}$ in the incubator at $37^{\circ} \mathrm{C}$ and washed with PBS, and the protein was extracted with solubilization buffer [ $25 \mathrm{~mm}$ Tris, $\mathrm{pH}$ 7.4, with $150 \mathrm{~mm} \mathrm{NaCl}, 1 \mathrm{~mm}$ EDTA, 5 mм NEM (Sigma), $200 \mu \mathrm{M}$ PMSF (Sigma), protease inhibitor mixture tablet (Roche Products), and $0.5 \%$ Triton X-100]. The lysate was centrifuged at $10,000 \times g$ for $20 \mathrm{~min}$ at $4^{\circ} \mathrm{C}$, and the protein concentration in the supernatants was determined using a Bio-Rad DC Protein Assay kit. Approximately $20 \mu \mathrm{g}$ of protein was incubated with $\mathrm{N}$-glycosidase F (PNGaseF) or endoglycosidase H (EndoH) (New England Biolabs, Beverly, MA) for $2 \mathrm{hr}$ at $37^{\circ} \mathrm{C}$, separated by $10 \%$ SDSPAGE, transferred to a polyvinylidene difluoride membrane, and blotted with the primary MAB369 anti-DAT antibody (1:1000; Chemicon) and secondary horseradish peroxidase-coupled goat anti-rat antibody (1:2000; Pierce) in blocking solution (TBS buffer with 3\% Carnation dry milk and $0.05 \%$ Tween 20 ). The protein was visualized with SuperSignal (Pierce) according to the protocol of the manufacturer.

Membrane preparation from HEK293 cells. Transiently transfected HEK293 cells were harvested the day after transfection. Selected cells were incubated with $100 \mu \mathrm{M}$ chloroquine for $10 \mathrm{hr}$ before preparation of the membranes. The cells were washed in PBS and lysed in ice-cold lysis buffer ( $25 \mathrm{~mm} \mathrm{Na}_{2} \mathrm{HPO}_{4}-\mathrm{NaH}_{2} \mathrm{PO}_{4}$ buffer, $\mathrm{pH}$ 7.4) containing $1 \mathrm{~mm}$ EDTA and protease inhibitors ( $10 \mu \mathrm{g} / \mathrm{ml}$ benzamidine, $10 \mu \mathrm{g} / \mathrm{ml}$ leupeptin, and $0.5 \mathrm{~mm}$ PMSF; all from Sigma), scraped off with a rubber policeman, and homogenized in a $15 \mathrm{ml}$ Dounce homogenizer on ice with 25 strokes using a type B piston. The lysate was centrifuged for $5 \mathrm{~min}$ at $500 \times g$, and the resulting supernatant was centrifuged at $40,000 \times g$ for $30 \mathrm{~min}$ at $4^{\circ} \mathrm{C}$. The membrane pellet was resuspended in ice-cold lysis buffer by several passages through a hypodermic needle, the protein was determined using the Bio-Rad DC protein assay kit, and the membranes were diluted to $1 \mathrm{mg} / \mathrm{ml}$ protein in lysis buffer before storage at $-80^{\circ} \mathrm{C}$.

Binding assay. Membrane protein $(10 \mu \mathrm{g})$, prepared from HEK293 cells as described above, was assayed in a total volume of $250 \mu \mathrm{l}$ using a sodium phosphate buffer $\left(50 \mathrm{mM} \mathrm{Na}_{2} \mathrm{HPO}_{4}-\mathrm{NaH}_{2} \mathrm{PO}_{4}\right.$, $\mathrm{pH}$ 7.4) containing $\sim 0.25 \mathrm{~nm}\left[{ }^{125} \mathrm{I}\right] \mathrm{RTI}-55$ (PE Applied Biosystems, Foster City, CA) and increasing concentrations of competing nonlabeled RTI-55. Nonspecific binding was assessed in the presence of $1 \mathrm{~mm}$ dopamine. Membranes were incubated for $3 \mathrm{hr}$ at room temperature before separation of bound from unbound ligand by rapid filtration over glass fiber filters (FilterMat B; Wallac, Turku, Finland) using a Tomtec 96-well cell harvester. MeltiLex Melt-on scintillator sheets (Wallac) were used for counting the filter in a Wallac Tri-Lux $\beta$-scintillation counter. All determinations were performed in triplicate.

PICK1 pull-down by glutathione S-transferase fusion proteins. The 24 $\mathrm{C}$-terminal residues of the hDAT were expressed as a glutathione $S$-transferase (GST) fusion protein by insertion of the corresponding coding sequence into pET4la (MfeI-XhoI) (Novagen, Madison, WI). Mutations were made in this construct by PCR as described above. The constructs were transformed into BL21 DE3 pLysS (Novagen) bacteria, and protein expression was induced at $30^{\circ} \mathrm{C}$ by $0.2 \mathrm{~mm}$ isopropyl- $\beta$-Dthiogalactopyranoside for $3 \mathrm{hr}$. The GST fusions were isolated by affinity purification to glutathione-Sepharose 4B (Amersham Biosciences). The rat PICK1 (cDNA kindly provided by Dr. Kumlesh Dev) was also made by insertion of a FLAG tag, followed by the cDNA into pET41a, expressed as GST fusion and purified on glutathione-Sepharose 4B beads. PICK1 was released from the beads by thrombin cleavage. Purified PICK1 and glutathione beads with the C-terminal DAT-GST fusions were combined in PBS and incubated with rapid shaking for $30 \mathrm{~min}$ at room temperature. The beads were washed three times with ice-cold PBS containing $0.5 \%$ Triton X-100. The bound GST fusion and PICK1 was eluted by incubation in $2 \times$ loading buffer $(100 \mathrm{~mm}$ Tris- $\mathrm{HCl}, \mathrm{pH} 6.8,20 \%$ glycerol, $10 \%$ SDS, $0.1 \mathrm{~m} \mathrm{DTT}$, and $0.2 \%$ bromophenol blue) for $5 \mathrm{~min}$ at $37 \mathrm{C}$. The proteins were separated by $15 \%$ SDS-PAGE, and proteins were detected by GelCode stain (Pierce).

Cross-linking. Cross-linking was performed as described previously (Hastrup et al., 2001; Hastrup and Javitch, 2003). Briefly, HEK293 cells, stably transfected with the appropriate hDAT construct, were washed with buffer ( $130 \mathrm{~mm} \mathrm{NaCl}, 1.3 \mathrm{~mm} \mathrm{KCl}, 1.2 \mathrm{~mm} \mathrm{MgSO}_{4}, 1.2 \mathrm{~mm} \mathrm{KH}_{2} \mathrm{PO}_{4}$, $2.2 \mathrm{~mm} \mathrm{CaCl}_{2}, 10 \mathrm{~mm}$ glucose, and $10 \mathrm{~mm}$ HEPES, $\mathrm{pH}$ 7.4) and reacted for $5 \mathrm{~min}$ at room temperature with either $1000 \mu \mathrm{M}$ copper sulfate or $100 \mu \mathrm{M}$ copper sulfate and $400 \mu \mathrm{M} \mathrm{Cu}{ }^{2+}$-phenanthroline (CuP). After crosslinking, the cells were washed twice with $2 \mathrm{ml}$ of buffer and reacted 20 min at room temperature with $10 \mathrm{~mm}$ NEM to block free sulfhydryl groups. Subsequently, the cells were harvested, solubilized, and processed for SDS-PAGE and immunoblotting as described previously (Hastrup et al., 2001; Hastrup and Javitch, 2003).

Data calculations. Uptake and binding data were analyzed by nonlinear regression analysis using Prism 3.0 from GraphPad Software (San Diego, $\mathrm{CA})$. The $\mathrm{IC}_{50}$ values used in the estimation of $K_{\mathrm{M}}$ or $K_{\mathrm{D}}$ were calculated from means of $\mathrm{pIC}_{50}$ values and the SE interval from the $\mathrm{pIC}_{50} \pm \mathrm{SE}$.

\section{Results}

\section{Changing the PDZ target sequence subtype in hDAT}

PDZ domain interactions are classically divided into two major categories: type 1 interactions, in which the extreme $\mathrm{C}$ terminus of the target protein terminates with a Ser/Thr-X- $\phi$ sequence, and type 2 interactions, in which the extreme $C$ terminus of the target protein terminates with an $\phi$-X- $\phi$ sequence ( $\mathrm{X}$ is any residue and $\phi$ is a hydrophobic residue) (Sheng and Sala, 2001; Hung and Sheng, 2002). The hDAT contains the putative type 2 $\mathrm{PDZ}$ domain-binding sequence $\mathrm{L}-\mathrm{K}-\mathrm{V}^{\star}$ (in which ${ }^{*}$ indicates the $\mathrm{C}$-terminal end of the protein) proposed to be critical for the interaction with PDZ domain-containing proteins, such as the scaffolding protein PICK1 (Torres et al., 2001). To assess the importance of the hDAT type 2 target sequence in relation to transporter function and targeting, we constructed two mutants in which the $\mathrm{L}-\mathrm{K}-\mathrm{V}^{\star}$ sequence was deleted $(\Delta \mathrm{LKV})$ or was substituted with $\mathrm{S}-\mathrm{L}-\mathrm{L}^{*}$, a type $1 \mathrm{PDZ}$ domain-binding sequence present in the $\beta_{2}$-adrenergic receptor and known to interact with other PDZ domain proteins (Hall et al., 1998; Cao et al., 1999; Gage et al., 2001). This change of the hDAT sequence from a type 2 to a type 1 sequence would be expected to result in the interaction of the modified transporter with a different subset of cellular proteins and thus possibly altered cellular regulation. 

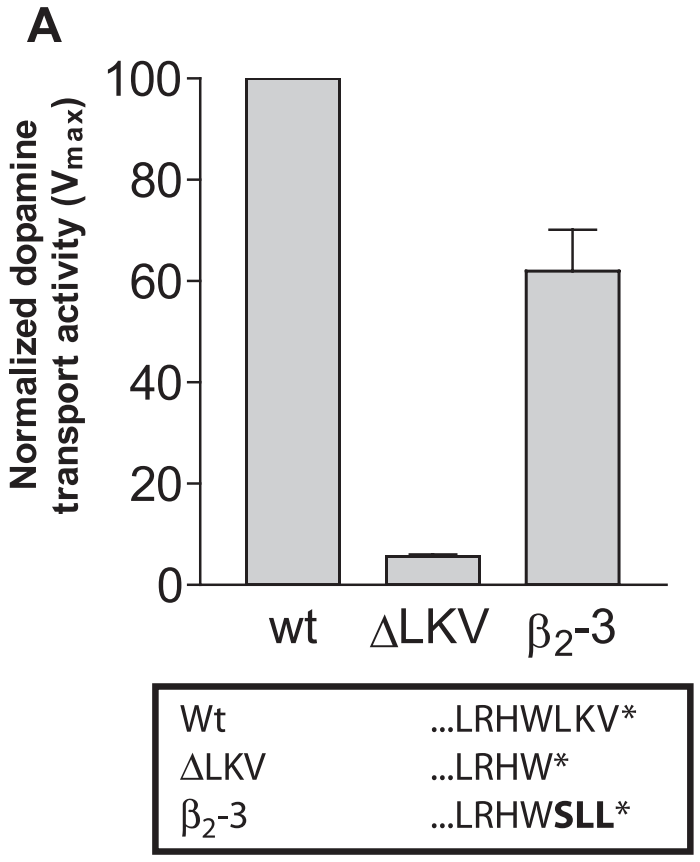

B

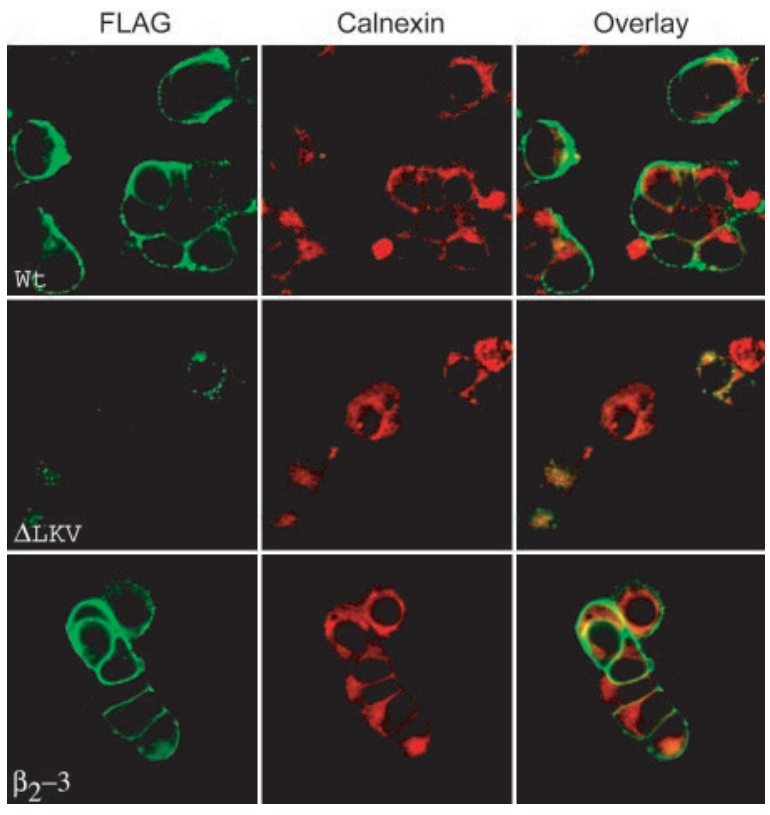

Figure 1. Functional consequences of deleting the $\mathrm{C}$-terminal PDZ type 2 binding sequence LKV in hDAT $(\Delta \mathrm{LKV})$ or converting it to the type 1 binding sequence of the $\beta_{2}$-adrenergic receptor (SLL $\left.=\beta_{2}-3\right) \cdot A,\left[{ }^{3} \mathrm{H}\right]$ dopamine uptake in HEK293 cells expressing WT, $\Delta L K V$, or $\beta_{2}-3$ (SLL). Data are $V_{\max }$ in percentage of WT (means \pm SE of 3 experiments). The $V_{\max }$ values are given in Table 1. $B$, Immunostaining of HEK293 cells expressing WT, $\Delta L K V$, or $\beta_{2}$-3-tagged $\mathrm{N}$-terminally with the FLAG epitope. The cells were fixed and incubated with primary antibody (mouse monoclonal M2 anti-FLAG antibody and rabbit anti-calnexin antibody), followed by secondary antibody (goat anti-mouse Alexa Fluor 488 and goat anti-rabbit Alexa Fluor 568) and visualization by confocal fluorescence microscopy, as described in Materials and Methods. The anti-FLAG staining is shown on the left, the anti-calnexin is in the middle, and the overlay is on the right.

In agreement with the observations by Torres et al. (2001), we observed a substantial loss of $\left[{ }^{3} \mathrm{H}\right]$ dopamine uptake activity of $\Delta \mathrm{LKV}$ in transfected HEK293 cells (Fig. $1 A$ ). This was attributable to a marked decrease in $V_{\max }$, with essentially no change in
Table 1. Dopamine uptake characteristics for WT and hDAT mutants expressed in HEK293 cells

\begin{tabular}{lccl}
\hline hDAT constructs & $n$ & $V_{\max } \pm S E$ (relative to WT) & $K_{\mathrm{M}}(\mu \mathrm{m})[$ SE interval $]$ \\
\hline WT & 10 & $100 \%$ & $0.42[0.36-0.48]$ \\
$\Delta$ LKV & 3 & $5.6 \pm 0.2 \%$ & $0.21[0.18-0.24]$ \\
HHH & 3 & $10.7 \pm 0.6 \%$ & $0.21[0.18-0.25]$ \\
$\beta_{2}-3$ & 3 & $62.0 \pm 8.1 \%$ & $0.45[0.43-0.46]$ \\
$\beta_{2}-8$ & 2 & $17.5 \pm 3.0 \%$ & $0.23[0.19-0.28]$ \\
$\beta_{2}-13$ & 2 & $11.9 \pm 1.8 \%$ & $0.25[0.24-0.26]$ \\
$\beta_{2}-23$ & 3 & $13.8 \pm 1.8 \%$ & $0.34[0.29-0.39]$ \\
$\beta_{2}-23(-S L L)$ & 3 & $13.2 \pm 2.2 \%$ & $0.50[0.45-0.56]$ \\
+Ala & 3 & $65.5 \pm 12.8 \%$ & $0.48[0.42-0.55]$ \\
+Tyr & 3 & $68.8 \pm 1.8 \%$ & $0.44[0.43-0.46]$ \\
3xAla_618-620 & 3 & $28.7 \pm 3.3 \%$ & $0.44[0.36-0.54]$ \\
3xAla_615-617 & 3 & $6.3 \pm 1.4 \%$ & $0.58[0.48-0.70]$ \\
3xAla_612-614 & 3 & $38.7 \pm 4.3 \%$ & $0.40[0.34-0.47]$ \\
3xAla_609-611 & 3 & $49.0 \pm 5.8 \%$ & $0.40[0.32-0.50]$ \\
3xAla_606-608 & 3 & $74.5 \pm 16.9 \%$ & $0.41[0.36-0.47]$ \\
3xAla_598-600 & 3 & $73.3 \pm 8.3 \%$ & $0.51[0.44-0.58]$ \\
\hline
\end{tabular}

$V_{\max }$ for WT hDAT was $1074 \pm 156 \mathrm{fmol} /$ min per $10^{5}$ cells (mean \pm SE). Each data point is normalized relative to WT hDAT from the same experiment.

$K_{\mathrm{M}}$ (Table 1). The decrease in $V_{\max }$ was most likely a consequence of decreased surface expression because immunofluorescence staining using the M2 antibody directed toward the N-terminal FLAG epitope revealed only intracellular staining of the $\Delta \mathrm{LKV}$ mutant, with no detectable staining of the plasma membrane (Fig. $1 B$ ). To identify the intracellular compartment in which the mutant was retained, we performed costaining with an antibody directed against calnexin, an ER resident chaperone protein. As seen in Figure $1 B$, there was clear overlap with the calnexin staining, supporting an ER localization of the $\Delta \mathrm{LKV}$ mutant. It is also noteworthy that the overall antibody staining for the mutant was very weak.

In contrast to $\triangle \mathrm{LKV}$, the SLL mutant displayed an uptake activity of $62 \pm 8 \%$ compared with that of WT hDAT (Table 1). In accordance with the uptake data, immunofluorescence experiments showed that the SLL staining was similar to that of the WT hDAT and thus predominantly found in the plasma membrane of the transfected HEK293 cells with very little intracellular staining (Fig. $1 B$ ). These data indicate that, although the $\mathrm{C}$ terminus is critical for plasma membrane expression of the transporter, the substitution of SLL for LKV is well tolerated. Thus, either PDZ domain interactions are not required for plasma membrane expression of the transporter, or, alternatively, a PDZ domain protein involved in hDAT surface targeting is of such promiscuous nature that it is able to interact with both the SLL and the LKV PDZ domain-binding sequences.

\section{Generation of non-PDZ binding mutants}

To further address the question of whether PDZ domain interactions are critical for expression of the hDAT on the cell surface, we generated an additional series of mutants with putative nonPDZ domain-interacting sequences: (1) substitution of L-K-V ${ }^{\star}$ with $\mathrm{H}-\mathrm{H}-\mathrm{H}^{\star}(\mathrm{HHH})$, which would be predicted to disrupt PDZ domain interaction, as well as other putative interactions, (2) addition of an alanine (+Ala) or tyrosine (+ Tyr) at the C terminus, which results in a positively charged lysine in the $\mathrm{P}_{-2}$ position (L-K-V-A* and L-K-V-Y*, respectively), making them very unlikely PDZ domain targets.

The HHH mutant displayed a substantial loss of $\left[{ }^{3} \mathrm{H}\right]$ dopamine activity (to only $10.7 \pm 0.7 \%$ of that of the WT hDAT), whereas both + Ala and + Tyr demonstrated much higher uptake levels comparable with that of the WT $(65.5 \pm 12.8 \%$ and $68.8 \pm$ 
A

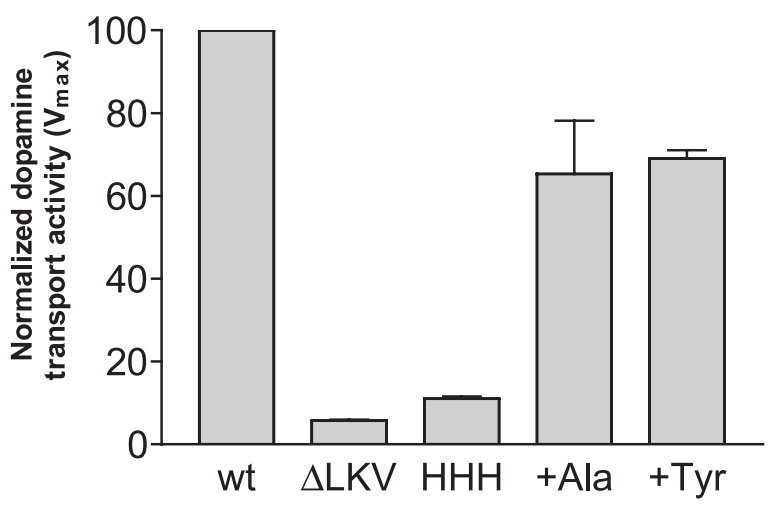

\begin{tabular}{|c|c|}
\hline Wt & ...LRHWLKV* \\
\hline$\Delta \mathrm{LKV}$ & ...LRHW* \\
\hline $\mathrm{HHH}$ & ...LRHWHHH* \\
\hline +Ala & ...LRHWLKVA* \\
\hline+ Tyr & ...LRHWLKVY* \\
\hline
\end{tabular}

B
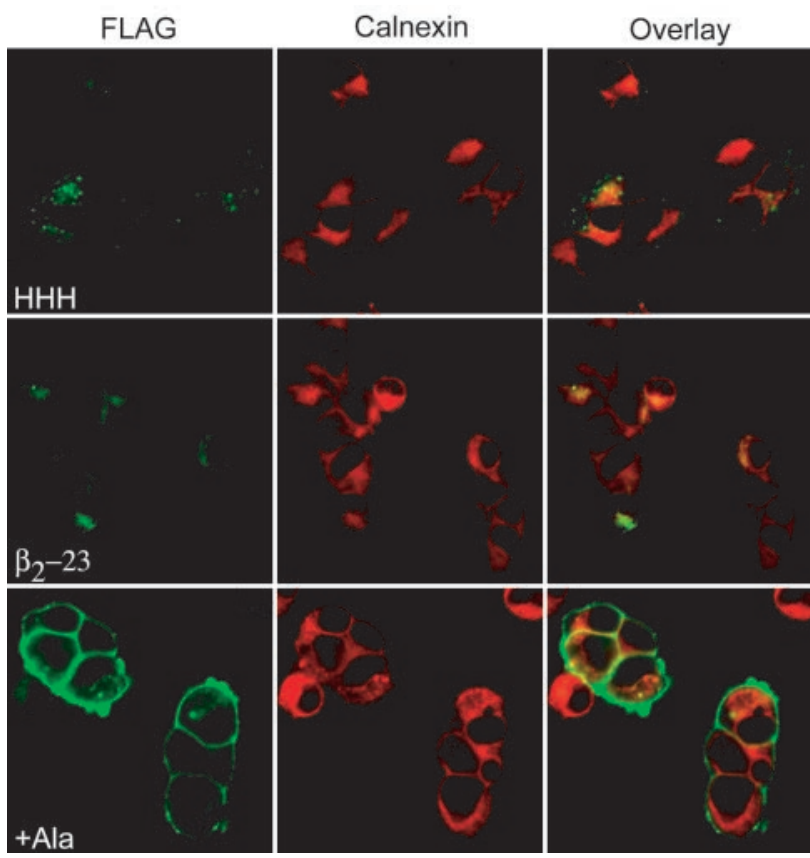

Figure 2. A, Uptake properties of non-PDZ domain-binding C-terminal mutations in hDAT $\left[{ }^{3} \mathrm{H}\right]$ dopamine uptake in HEK293 cells expressing WT, $\Delta \mathrm{LKV}, \mathrm{HHH},+\mathrm{Ala}$, or + Tyr. Data are $V_{\max }$ in percentage of WT (means \pm SE of $3-5$ experiments). The $V_{\max }$ values are given in Table 1. The C-terminal sequences of the WT and mutations are shown in the box. $B$, Immunostaining of HEK293 cells expressing $\mathrm{HHH}, \beta_{2}-23$, or + Ala tagged N-terminally with the FLAG epitope. The cells were fixed and incubated with primary antibody (mouse monoclonal M2 anti-FLAG antibody and rabbit anti-calnexin antibody), followed by secondary antibody (goat anti-mouse Alexa Fluor 488 and goat anti-rabbit Alexa Fluor 568) and visualization by confocal fluorescence microscopy, as described in Materials and Methods. The anti-FLAG staining is shown in the left panels, the anti-calnexin is in the middle panels, and the overlay is in the right panels.

$1.8 \%$, respectively) (Fig. $2 A$, Table 1 ). Consistent with the uptake data, immunofluorescence showed only intracellular staining of $\mathrm{HHH}$ (as seen with the $\Delta \mathrm{LKV}$ ), whereas + Tyr (data not shown) and + Ala displayed clear plasma membrane staining (Fig. $2 \mathrm{~B}$ ). Although we cannot fully exclude that the rather dramatic sub-
A
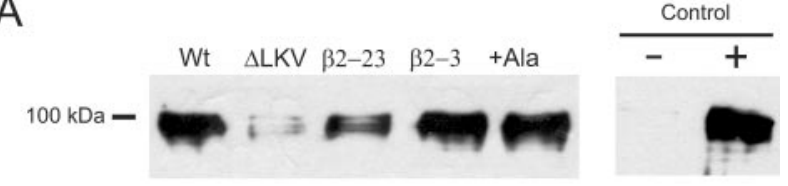

B
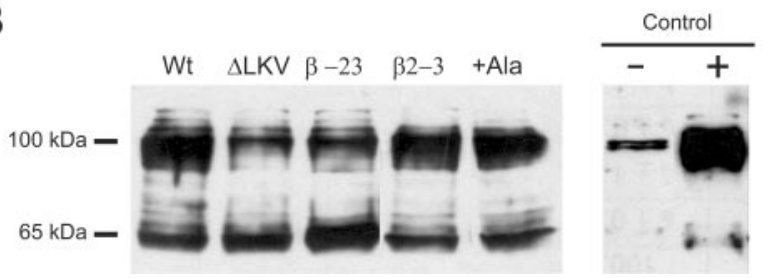

Figure 3. Surface expression of WT and mutants transporters assessed by biotinylation. $A$ Surface biotinylation of HEK293 cells expressing WT, $\Delta$ LKV, $\beta_{2}-23, \beta_{2}-3$, or + Ala (left). Comparison of nontransfected cells with WT transfected cells (right). Surface biotinylated protein was purified using streptavidin beads and analyzed by SDS-PAGE, followed by immunoblotting with the M2 anti-FLAG antibody, as described in Materials and Methods. The surface-expressed hDAT migrated as a single glycosylated band corresponding to a molecular weight of $\sim 90 \mathrm{kDa}$. $B$, SDS-PAGE and immunoblotting with the M2 anti-FLAG antibody of total cellular protein (15 $\mu \mathrm{g}$ ) from cells expressing WT, $\Delta \mathrm{LKV}, \beta_{2}-23, \beta_{2}-3$, or + Ala (left). Comparison of nontransfected cells with WT transfected cells is shown on the right. The fully mature $\mathrm{N}$-glycosylated $\mathrm{hDAT}$ is eluted corresponding to a molecular weight of $90 \mathrm{kDa}$, and an immature form is eluted at $\sim 60 \mathrm{kDa}$, in agreement with previous data (Hastrup et al., 2001). The gel shown is representative of at least three independent experiments.

stitution with $\mathrm{HHH}$ could create new unfavorable interactions in the cells, the similar phenotype of $\mathrm{HHH}$ and $\Delta \mathrm{LKV}$ further support an involvement of the extreme $\mathrm{C}$ terminus in surface targeting of the hDAT. Because both + Ala and + Tyr were efficiently targeted to the surface, this role is nevertheless unlikely to involve PDZ domain interactions.

\section{Surface biotinylation experiments}

The surface expression of WT hDAT and selected mutants in the transfected HEK-293 cells was assessed by surface biotinylation experiments using the membrane-impermeant biotinylation reagent sulfo-NHS-SS-biotin. Immunoblot analysis of the avidinpurified protein showed that both the SLL and +Ala mutants were expressed on the cell surface in amounts comparable with that of WT hDAT as reflected by the similar densities of the immunoreactive $\sim 90 \mathrm{kDa}$ hDAT band, which corresponds to the fully mature glycosylated transporter (Hastrup et al., 2001) (Fig. $3 A$ ). In further agreement with the uptake and immunofluorescence data, the density of the immunoreactive $\sim 90 \mathrm{kDa} \Delta \mathrm{LKV}$ band was substantially lower, consistent with minimal surface expression (Fig. 3A). Similarly, the surface expression of a mutant in which the $23 \mathrm{C}$-terminal residues of the hDAT were replaced with the corresponding sequence in the $\beta_{2}$-adrenergic receptor ( $\beta_{2}-23$, see below) was substantially reduced.

Immunoblotting analysis of the corresponding total cellular protein showed a pattern consistent with the analysis of the avidin-purified protein (Fig. $3 B$ ). In addition to the mature $\sim 90$ $\mathrm{kDa}$ band, a minor fraction of WT hDAT migrated as a sharper band of $\sim 60 \mathrm{kDa}$ (Fig. $3 B$ ). This immunoreactive band corresponds to an immaturely glycosylated and likely intracellularly retained form of the protein (Hastrup et al., 2001). Consistent with the uptake and immunofluorescence data, the distribution between the mature and immature forms of the SLL and the + Ala mutants were essentially identical to the WT hDAT (Fig. 3B). In contrast, very little of $\Delta \mathrm{LKV}$ was found in the mature $\sim 90 \mathrm{kDA}$ form, with the majority in the immature form (Fig. 3B). A similar 

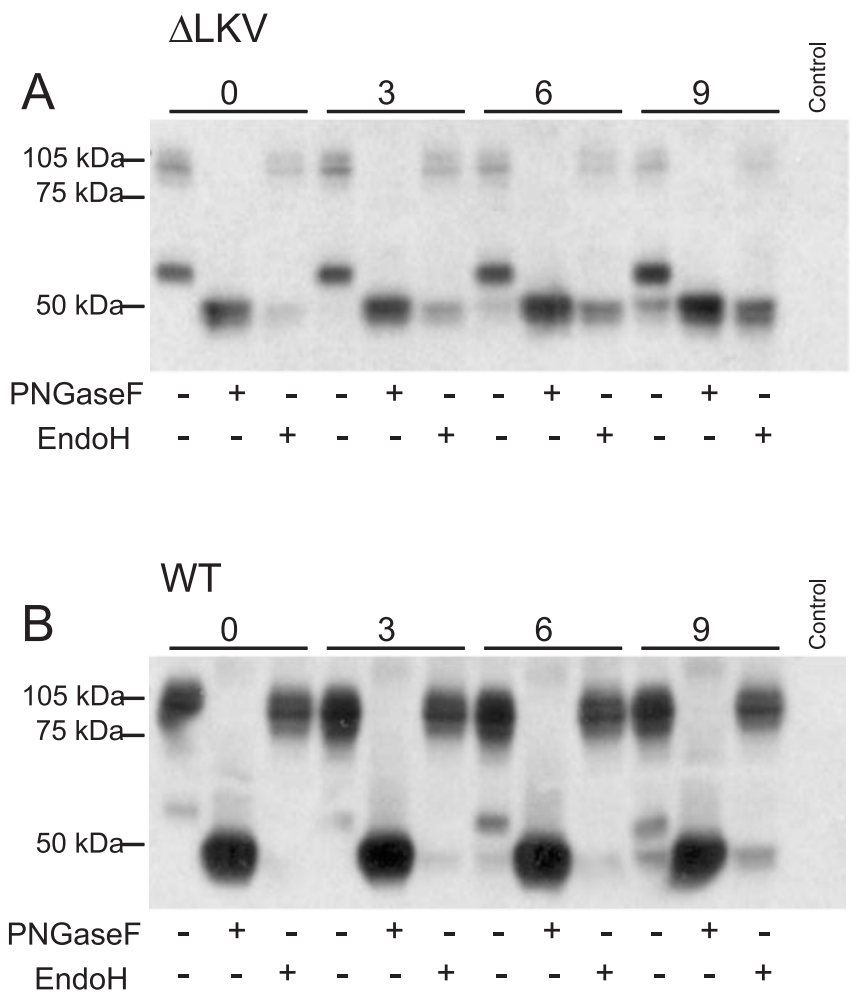

Figure 4. Effect of proteasome 265 inhibition on degradation of the DAT and $\Delta \mathrm{LKV}$ in HEK293 cells. $A$, The $\Delta$ LKV and the WT ( $B$ ) after incubation with MG132 for $0,3,6$, or $9 \mathrm{hr}$, followed by incubation with PNGaseF or EndoH. Samples were analyzed by SDS-PAGE, followed by immunoblotting with the MAB369 anti-DAT antibody, as described in Materials and Methods. The fully mature N-glycosylated hDAT, which is sensitive to PNGaseF, eluted corresponding to a molecular weight of $90 \mathrm{kDa}$. The immaturely glycosylated form, which is sensitive to EndoH, eluted at $\sim 60 \mathrm{kDa}$. Complete deglycosylation by PNGaseF or EndoH results in elution of the DAT at $\sim 50 \mathrm{kDa}$. Protein from untransfected cells is included in the right lane as control.

pattern was observed for a mutant in which the $23 \mathrm{C}$-terminal residues of the hDAT was replaced by the corresponding sequence from the $\beta_{2}$-adrenergic receptor $\left(\beta_{2}-23\right.$, see below). These data underline that particular residues in the $C$ terminus, but not an intact PDZ domain-binding sequence, are required for proper maturation of DAT.

\section{Assessment of ER retention after deletion of C-terminal PDZ-binding motif}

The observation that $\Delta \mathrm{LKV}$ existed mainly in an immature form (Fig. 3) and was localized to the ER (Fig. 1) is consistent with impaired ER export and rapid degradation of synthesized protein. To further substantiate this hypothesis, we performed experiments in which HEK293 cells expressing either WT or $\Delta \mathrm{LKV}$ were incubated with a $26 \mathrm{~S}$ proteasome inhibitor (MG132), followed by SDS-PAGE and immunoblotting analysis of the cell lysates. Note that ER-retained proteins are ultimately returned to the cytosol via the ER protein translocation pore, in which they are ubiquitinated and degraded by the $26 \mathrm{~S}$ proteasome (Vashist et al., 2001). Thus, if $\Delta \mathrm{LKV}$ is retained in the ER, inhibition of the $26 \mathrm{~S}$ proteasome should result in accumulation of immature transporter with little or no increase in the amount of mature transporter. The results of the experiment are shown in Figure 4. To verify that the immature band eluting at $\sim 60 \mathrm{kDa}$ did indeed represent ER-retained transporter, the cell extracts were incubated with either PNGaseF, which cleaves off all asparaginelinked oligosaccharides, or EndoH, which cleaves off only the high-mannose type of asparagine-linked oligosaccharides added in the ER. PNGaseF caused all transporters to elute at $\sim 45 \mathrm{kDa}$, consistent with complete deglycosylation of the transporter (Fig. 4). In contrast, EndoH only deglycosylated the $\sim 60 \mathrm{kDa}$ band, whereas the $\sim 90 \mathrm{kDa}$ band was insensitive, consistent with ER localization of the $\sim 60 \mathrm{kDa}$ band.

Incubation with the $26 \mathrm{~S}$ proteasome inhibitor MG132 clearly increased the amount of EndoH-sensitive $\Delta \mathrm{LKV}$ over the $9 \mathrm{hr}$ incubation period, with no change in the amount of mature transporter ( $\sim 90 \mathrm{kDa}$ band) (Fig. $4 A$ ). Densitometry analysis of the experiment revealed that the total amount of $\Delta \mathrm{LKV}$ (mature plus immature after EndoH treatment) at $t=9 \mathrm{hr}$ was increased to $291 \%$ of that observed at $t=0$ (Fig. $4 A$ ). This was attributable to an increase in the amount of the immature EndoH-sensitive form, i.e., at $t=9 \mathrm{hr}$ the amount of this was $493 \%$ of that observed at $t=0$, whereas at $t=9 \mathrm{hr}$ the amount of the mature form was reduced to $86 \%$ of that observed at $t=0$. In contrast, the total amount of WT (mature plus immature after EndoH treatment) only increased to $115 \%$ of that observed at $t=0$ (Fig. $4 B$ ). The amount of EndoH-sensitive protein was also increased in the WT; however, the amount of this immature protein relative to the amount of mature WT protein was very small and much lower than in $\Delta \mathrm{LKV}$, in which it accounted for the majority of the protein (Fig. 4).

\section{C-terminal substitutions with $\boldsymbol{\beta}_{2}$-adrenegic receptor sequence}

To define more precisely the structural epitopes in the extreme $\mathrm{C}$ terminus required for the proper targeting of hDAT, we progressively substituted the hDAT from the $\mathrm{C}$ terminus with the corresponding amino acid sequence from the $\beta_{2}$-adrenergic receptor (beyond the terminal S-L-L* sequence substituted earlier) resulting in $\beta_{2}-8, \beta_{2}-13$, and $\beta_{2}-23$ (Fig. $5 A$ ). Uptake experiments in HEK293 cells transfected with these constructs revealed that substitution of the eight $\mathrm{C}$-terminal residues with the corresponding $\beta_{2}$-adrenergic receptor sequence $\left(\beta_{2}-8\right)$ was sufficient to markedly impair the ability of the transporter to translocate $\left[{ }^{3} \mathrm{H}\right]$ dopamine across the plasma membrane (Fig. 5A). The reduction in uptake capacity was similar after substitution of a longer fragment of the hDAT tail $\left(\beta_{2}-13\right.$ and $\left.\beta_{2}-23\right)$ (Fig. $\left.5 A\right)$. Immunofluorescence analysis and surface biotinylation experiments showed, in agreement with the uptake data, that $\beta_{2}-23$ is retained intracellularly and is expressed at a much lower level at the cell surface than the WT hDAT (Figs. $2 B, 3 A$ ). Because the substitution of the three $\mathrm{C}$-terminal residues with that of the $\beta_{2}$ adrenergic receptor $\left(\beta_{2}-3\right)$ was tolerated for functional expression, whereas substitution of eight $\left(\beta_{2}-8\right)$ was not tolerated, it is likely that structural elements between residues 3 and 8 from the C terminus are critical for the proper expression of the transporter.

\section{C-terminal triple-Ala substitutions}

A potential risk of the chimeric approach is that the introduction of sequences from the chimeric partner might result in the introduction of new functional properties rather than in elimination of inherent functional properties from the protein of interest. We decided therefore also to perform consecutive triple-alanine substitutions within the $\mathrm{C}$ terminus of hDAT and compare the results with those obtained with chimeric $\beta_{2}$-adrenergic receptor substitutions. As shown in Figure $5 B$, the most marked reduction in $\left[{ }^{3} \mathrm{H}\right]$ dopamine uptake resulted from the substitution of residues 615-617 with alanines (3xAla_615-617, $V_{\max }$ of $6.3 \pm 1.4 \%$ of WT level) (Fig. 5B, Table 1). Substitution of the last three 


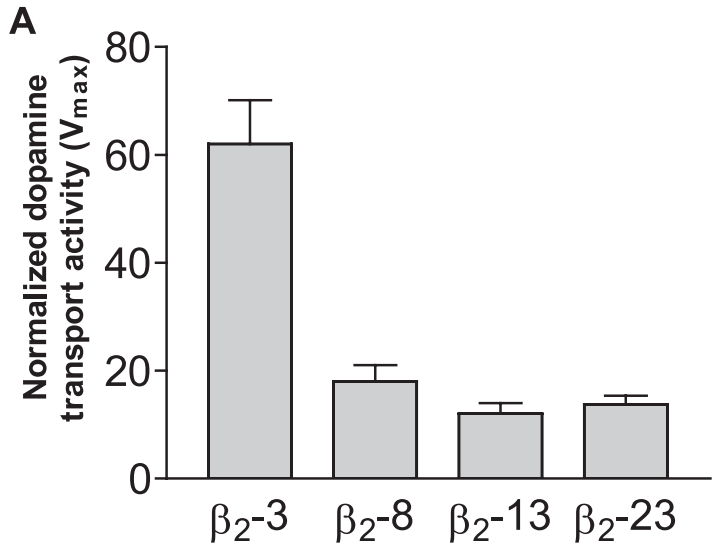

\begin{tabular}{ll|}
\hline $\mathrm{Wt}$ & $\ldots$..IAPEKDRELVDRGEVRQFTLRHWLKV* \\
$\beta_{2-3}$ & $\ldots$..IAPEKDRELVDRGEVRQFTLRHWSLL* \\
$\beta_{2-8}$ & ...IAPEKDRELVDRGEVRQFCSTNDSLL* \\
$\beta_{2-13}$ & ..IAPEKDRELVDRGSQGRNCSTNDSLL* \\
$\beta_{2-23}$ & ...IAPQGTVPSDNIDSQGRNCSTNDSLL*
\end{tabular}

\section{B}
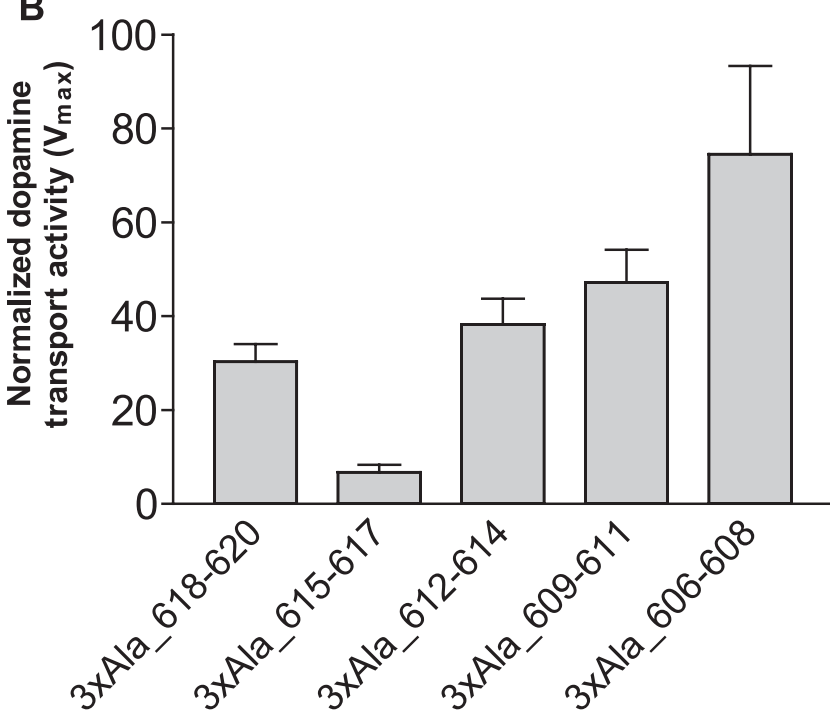

Figure 5. Uptake properties of C-terminal hDAT mutations. A, Progressive substitutions of the hDAT C terminus with the corresponding sequences from the human $\beta_{2}$-adrenergic receptor (containing the consensus type 1 PDZ domain target sequence $S-L-L^{*}$ ). The data are relative $\left[{ }^{3} \mathrm{H}\right]$ dopamine uptake $\left(V_{\max }\right.$ in percentage of WT; means \pm SE of $3-5$ experiments) in HEK293 cells expressing $\beta_{2}-3, \beta_{2}-8, \beta_{2}-13$, or $\beta_{2}-23$. $B$, Consecutive triple-alanine substitutions in the hDAT C terminus. The data are relative $\left[{ }^{3} \mathrm{H}\right]$ dopamine uptake $\left(V_{\max }\right.$ in percentage of WT; means \pm SE of 3-5 experiments) in HEK293 cells expressing 3xAla_606-608, 3xAla_609611, 3xAla_612-614,3xAla_615-617, or 3xAla_618-620. The $V_{\max }$ values are given in Table 1. The C-terminal sequences of the WT and mutations are shown in the boxes.

C-terminal residues (3xAla_618-620), as well as of residues 612614 (3xAla_612-614) and 609-611 (3xAla_609-611), also reduced the $V_{\max }$ for $\left[{ }^{3} \mathrm{H}\right.$ ]dopamine uptake but only to $30-50 \%$ of that of the WT (Fig. 5B, Table 1). Substitution of residues $606-$ 608 (3xAla_606-608) reduced only uptake capacity to $\sim 75 \%$ of

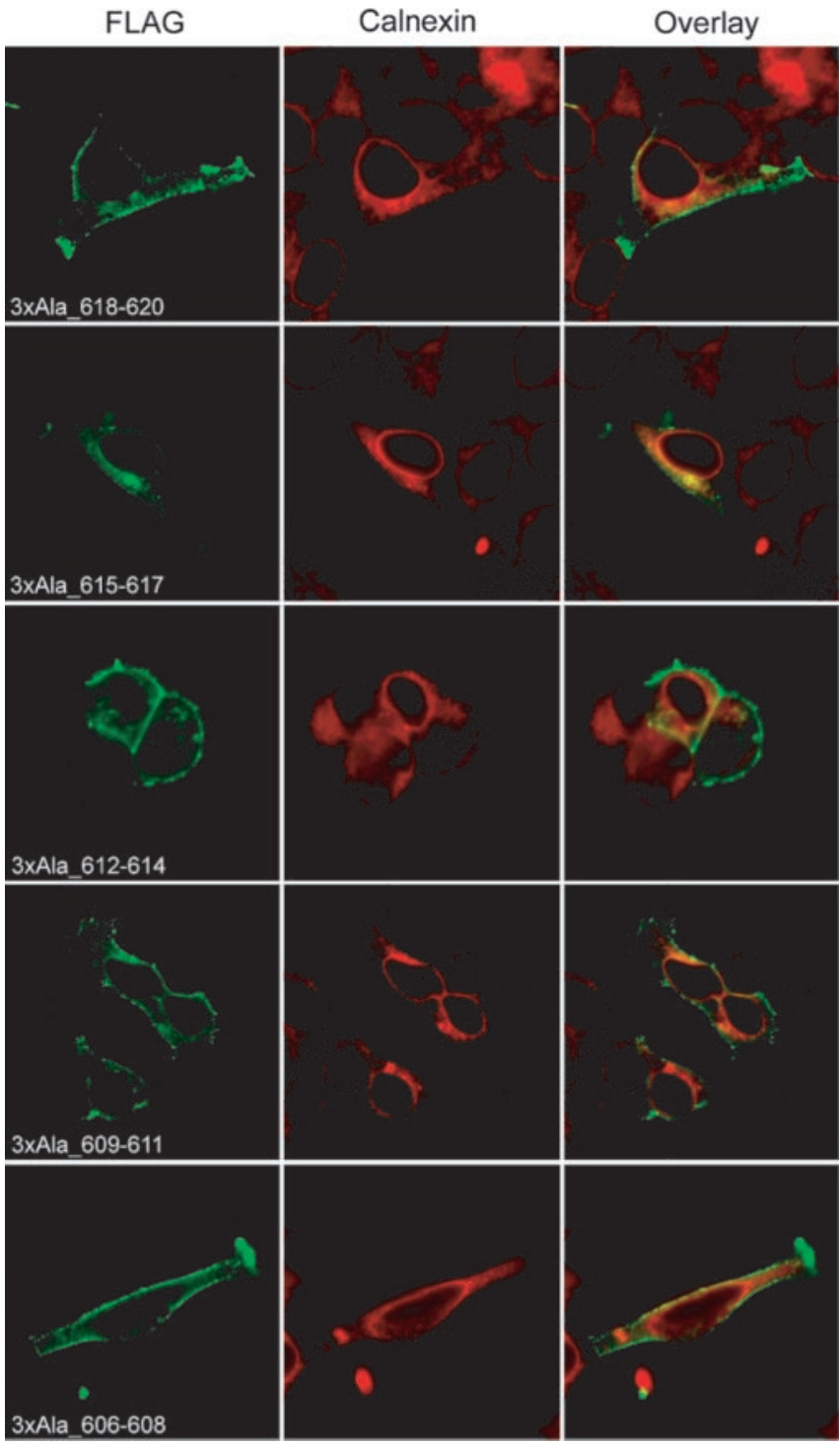

Figure 6. Immunostaining of HEK293 cells expressing 3xAla_606-608, 3xAla_609-611, 3xAla_612-614, 3xAla_615-617, or 3xAla_618-620 tagged N-terminally with the FLAG epitope. The cells were fixed, incubated with primary antibody (mouse monoclonal M2 antiFLAG antibody and rabbit anti-calnexin antibody), followed by secondary antibody (goat antimouse Alexa Fluor 488 and goat anti-rabbit Alexa Fluor 568) and visualization by confocal fluorescence microscopy, as described in Materials and Methods. The anti-FLAG staining is shown on the left, the anti-calnexin is in the middle, and the overlay is on the right.

that of WT (Fig. 5B, Table 1). Parallel immunofluorescence experiments showed, in accordance with the uptake data, that 3xAla_615-617 could not be detected in the plasma membrane but was localized intracellularly in reduced amounts with a pattern overlapping with that of the ER marker calnexin (Fig. 6). In contrast, 3xAla_618-620,3xAla_612-614,3xAla_609-611, and 3xAla_606-608 were all found in the plasma membrane, although the ratio between intracellular and plasma membrane staining tended to be larger, especially in 3xAla_618-620 and 3xAla_612-614 (Fig. 6) compared with WT hDAT or the SLL and +Ala hDAT mutants (Figs. 1, 2 B, respectively). Overall, these results are very similar to those obtained with the $\beta_{2}$-adrenergic receptor substitutions (Fig. 5A). The slightly more pronounced effect of 3xAla_615-617 compared with $\beta_{2}-8$ likely reflects that the $\beta_{2}$ receptor sequence is a better functional substitute than three alanines in positions 615-617. 
We also mutated residues 600-602 to Ala (3xAla_598-600) to remove a well conserved diacetic motif (DXE) (X indicates any residue). Diacetic motifs might act as forward ER export signals (Barlowe, 2003); however, because 3xAla_598-600 displayed uptake properties and, therefore, presumably functional surface expression similar to the WT (Table 1), such a role of Asp598 and Glu600 seems very unlikely.

\section{$\left[{ }^{325} \mathrm{H}\right] \mathrm{RTI}-55$ binding assays}

Crude membranes were prepared of HEK293 cells transiently expressing the WT hDAT or selected mutants. The membranes were used in radioligand binding assays using the cocaine analog $\left[{ }^{125} \mathrm{I}\right] \mathrm{RTI}-55$. The binding data corresponded to our observations in the $\left[{ }^{3} \mathrm{H}\right]$ dopamine uptake assay. Both $\Delta \mathrm{LKV}$ and 3xAla_615-617 displayed very low [ $\left.{ }^{125} \mathrm{I}\right] \mathrm{RTI}-55$ binding activity compared with the WT $(4.0 \pm 2.2$ and $2.9 \pm 0.7 \%$, respectively) and the 3xAla_618-620 mutant displayed $21.2 \pm 3.3 \%$ of WT binding activity, whereas + Ala retained $74.1 \pm 3.4 \%$ binding activity (mutant binding data are normalized relative to WT, and data are means \pm SE of three experiments done in triplicate; the $B_{\max }$ value for WT was $930 \pm 160 \mathrm{fmol} / \mathrm{mg}$ protein). No changes in $\left[{ }^{125} \mathrm{I}\right] \mathrm{RTI}-55$ affinity was observed for the different mutants (data not shown). SDS-PAGE of the membranes followed by immunoblotting showed the presence of the ER marker calnexin in the membranes, confirming that the membranes not only contained plasma membrane fragments but also membranes derived from intracellular compartments, such as the ER (data not shown). Accordingly, the binding assay should, in contrast to the uptake assay, not only detect surface-targeted transporter but also intracellularly retained transporter if present in a functional form. The similarity between the uptake data and the binding data suggest that there is no intracellular transporter present in a functional form capable of binding $\left[{ }^{125} \mathrm{I}\right] \mathrm{RTI}-55$. This might be attributable to misfolding of the intracellularly retained transporter resulting in too low $\left[{ }^{125} \mathrm{I}\right] \mathrm{RTI}-55$ affinity for detection in the binding assays and/or the lower $B_{\max }$ value for the intracellularly retained mutants might reflect a reduction in the overall number of transporter molecules.

We also prepared membranes from cells that had been exposed for $10 \mathrm{hr}$ to $100 \mu \mathrm{M}$ chloroquine to inhibit proteolytic degradation in lysosomes; however, no effect of this treatment could be detected (data not shown). This provides additional support to the notion that the reduced surface expression of mutants such as $\Delta$ LKV and 3xAla_615-617 is attributable to ER retention followed by proteasomal degradation and not attributable to impaired anchoring in the plasma membrane leading to increased constitutive trafficking to lysosomes.

\section{Expression of C-terminal mutants in N2A cells}

To validate our results obtained in HEK293 cells in a neuronally derived cell line, we used the neuroblastoma cell line N2A. Importantly, these cells express appreciable amounts of PICK1, in contrast to HEK293 cells in which PICK1 expression is hardly detectable by immunoblot analysis (data not shown). Similar to our observation in the HEK293 cells, deletion of the last three residues $(\Delta \mathrm{LKV})$ essentially eliminated measurable $\left[{ }^{3} \mathrm{H}\right]$ dopamine uptake in these cells (Table 2). Additionally, both the $\beta_{2}-8$ and $\beta_{2}-23$ mutations displayed very low uptake ( $<10 \%$ of WT), whereas the predicted non-PDZ-binding mutants +Ala and + Tyr as well as SLL were much less affected, with $V_{\max }$ values of between 40 and $60 \%$ of that of the WT (Table 2). For the tripleAla substitutions, we observed, as in the HEK293 cells, the most dramatic reduction in uptake in 3xAla_615-617 ( 5\% of WT
Table 2. Dopamine uptake characteristics for WT and hDAT mutants expressed in N2A cells

\begin{tabular}{llll}
\hline hDAT constructs & $n$ & $V_{\max } \pm \mathrm{SE}$ (relative to WT) & $K_{\mathrm{M}}(\mu \mathrm{m})[$ SE interval] \\
\hline WT & 9 & $100 \%$ & $0.30[0.27-0.24]$ \\
$\Delta \mathrm{LKV}$ & 4 & $2.2 \pm 0.8 \%$ & $0.20[0.15-0.26]$ \\
HHH & 5 & $5.4 \pm 1.6 \%$ & $0.15[0.10-0.22]$ \\
$\beta_{2}-3$ & 6 & $46.2 \pm 6.2 \%$ & $0.39[0.32-0.46]$ \\
$\beta_{2}-23$ & 4 & $7.5 \pm 4.0 \%$ & $0.35[0.32-0.39]$ \\
$\beta_{2}-23(-S L L)$ & 4 & $8.2 \pm 3.5 \%$ & $0.38[0.30-0.48]$ \\
+ Ala & 5 & $39.6 \pm 4.0 \%$ & $0.35[0.29-0.41]$ \\
+ Tyr & 3 & $61.9 \pm 9.7 \%$ & $0.29[0.29-0.30]$ \\
3xAla_618-620 & 3 & $14.3 \pm 0.6 \%$ & $0.22[0.19-0.25]$ \\
3xAla_615-617 & 3 & $6.3 \pm 2.7 \%$ & $0.67[0.43-1.04]$ \\
3xAla_612-614 & 3 & $15.4 \pm 5.1 \%$ & $0.19[0.13-0.27]$ \\
3xAla_609-611 & 3 & $41.0 \pm 3.1 \%$ & $0.20[0.16-0.25]$ \\
3xAla_606-608 & 3 & $44.1 \pm 4.0 \%$ & $0.27[0.23-0.33]$ \\
3xAla_598-600 & 3 & $62.2 \pm 3.7 \%$ & $0.22[0.21-0.22]$ \\
\hline
\end{tabular}

$V_{\max }$ for WT hDAT was $634 \pm 55 \mathrm{fmol} / \mathrm{min}$ per $10^{5}$ cells (mean $\pm \mathrm{SE}$ ). Each data point is normalized relative to WT hDAT from the same experiment.

uptake) (Table 2). The 3xAla_618-620 and 3xAla_612-614 mutants were less affected ( $\sim 15 \%$ of WT uptake) (Table 2$)$, whereas the 3xAla_609-611 and 3xAla_606-608 mutants displayed an uptake capacity of $\sim 40 \%$ of that of the WT (Table 2 ). Thus, overall we observed a similar picture in the N2A cells, although the effects of the mutants generally were more pronounced than in the HEK293 cells (compare Tables 1,2).

To explore these observations further, the expression of the different C-terminal mutants was evaluated by immunofluorescence in N2A cells that were either undifferentiated (data not shown) or differentiated with $2 \mathrm{~mm}$ dibutyryl-cAMP for $2 \mathrm{~d}$. This treatment caused outgrowth of neurites that allowed us to test whether the C-terminal mutants affected targeting to specialized neuronal compartments. In the differentiated cells, the WT was expressed in the plasma membrane of the "soma" and was also efficiently targeted to the sprouting neurites (Fig. 7). The predicted non-PDZ-binding mutant + Ala was also observed in the plasma membrane of the soma and targeted efficiently to the neurites (Fig. 7). The same was the case for the SLL mutant containing a type 1 PDZ-binding sequence, whereas $\mathrm{HHH}$ and $\beta_{2}-23$ were retained inside the cell, showing a considerable overlap with the staining for calnexin (Fig. 7). As expected, 3xAla_615-617 also displayed exclusively intracellular staining with no detectable staining in the neurites (Fig. 7). In contrast, 3xAla_618-620, 3xAla_612-614, and 3xAla_609-611 were, similar to the WT, found in the plasma membrane of the soma and in the neurites (Fig. 7). These observations in differentiated N2A cells altogether support the hypothesis that residues within the $\mathrm{C}$ terminus of hDAT, and in particular residues 615-617, are essential for proper cellular targeting of the transporter to the cell surface, as well as into neuronal processes. Importantly, the data also suggest that neither plasma membrane insertion nor targeting into neurites of hDAT are dependent on PDZ domain interactions.

\section{Assessment of interaction between C-terminal mutants and the PDZ domain of PICK1}

To evaluate directly whether our C-terminal mutants had lost or retained their ability to form PDZ domain interactions, we first generated C-terminal GST fusion proteins of the $24 \mathrm{C}$-terminal residues of the WT hDAT and of the selected mutants $+\mathrm{Ala}, \beta_{2}-3$, 3xAla_618-620, and 3xAla_615-617. The purified GST fusion proteins attached to glutathione beads were incubated with purified PICK1 for $30 \mathrm{~min}$, washed with ice-cold PBS, and eluted 

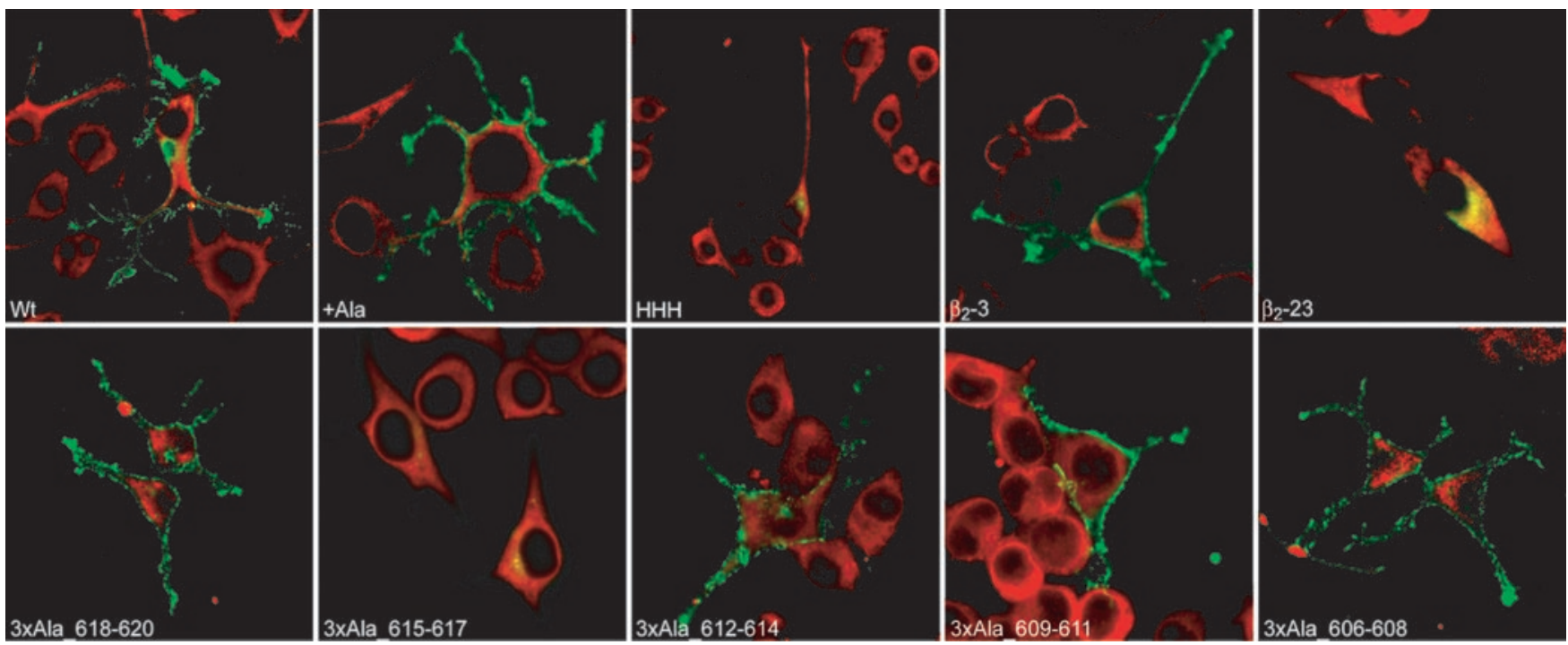

Figure 7. Immunostaining of N2A cells differentiated with dibutyryl-cAMP and expressing WT, +Ala, HHH, $\beta_{2}-3, \beta_{2}-23,3 x A l a \_618-620,3 x A l a \_615-617,3 x A l a \_612-614,0$ or 3xAla_609611. All constructs were tagged N-terminally with the FLAG epitope. The cells were fixed and incubated with primary antibody (mouse monoclonal M2 anti-FLAG antibody and rabbit anti-calnexin antibody), followed by secondary antibody (goat anti-mouse Alexa Fluor 488 and goat anti-rabbit Alexa Fluor 568) and visualization by confocal fluorescence microscopy, as described in Materials and Methods.

GST GST-CT GST-CT GST-CT GST-CT GST-CT PICK1 +Ala 3xAla 3xAla SLL alone 615-617 618-620

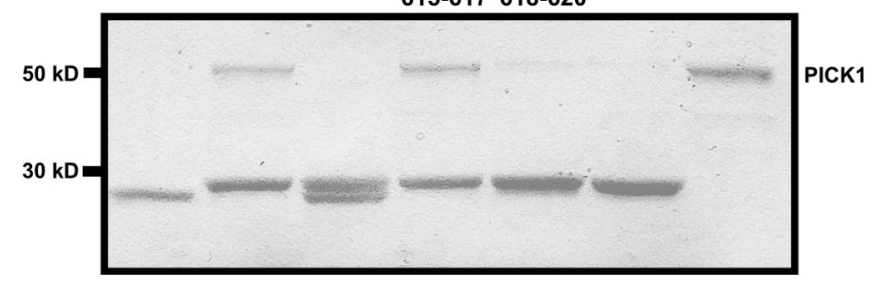

Figure 8. GST fusion proteins pull-down of purified PICK1. GST fusion proteins, bound to glutathione beads and containing the last 24 residues of the WT (GST-CT) and indicated mutants thereof, were incubated with purified PICK1 for 30 min at room temperature, washed with ice-cold PBS, and eluted with loading buffer before separation by SDS-PAGE. A representative gel stained with GelCode stain (Pierce) is shown.

with loading buffer before separation by SDS-PAGE. A GelCode stain of the resulting gel showed no pull-down of the PDZ domain of PICK1 with GST alone (Fig. 8) or with an N-terminal hDAT GST fusion protein (data not shown). In contrast, a band corresponding in size to PICK1 was clearly visible in the presence of the WT C-terminal GST fusion protein, consistent with the ability of the WT hDAT C terminus to interact with the PDZ domain of PICK1 (Fig. 8). In contrast, the PICK1 band was not precipitated by the + Ala or the 3xAla_618-620 GST fusion proteins, consistent with the predicted impaired ability of these mutants to bind PICK1. The SLL GST fusion protein was also unable to bind PICK1 (Fig. 8). Interestingly, the 3xAla_615-617 fusion protein efficiently precipitated PICK1, strongly suggesting that 3xAla_615-617 can bind the PDZ domain of PICK1 with similar affinity as the WT (Fig. 8). This is particularly interesting because this mutant, as described above, is retained intracellularly, yet it has preserved its ability to interact with PICK1.

We wanted to verify these observations in living cells. Because the endogenous levels of PICK1 in HEK293 cells were found to be very low (data not shown), we stably expressed EFGP-tagged PICK1 in HEK293 cells either alone or together with WT, 3xAla_615-617,3xAla_618-620,or + Ala. Confocal microscopy analyses of these cell lines revealed that, in cells expressing EGFPPICK1 alone, all fluorescence was evenly distributed in the cytoplasm. However, in cells coexpressing WT and EGFP-PICK1, essentially all EGFP-PICK1 fluorescence was observed in the plasma membrane and overlapped with WT immunostaining, consistent with efficient interaction between WT and EGFPPICK1 (Fig. 9). In contrast and consistent with lack of interaction between EGFP-PICK1 and + Ala or 3xAla_618-620, all EGFPPICK1 fluorescence was evenly distributed in the cytoplasm in cells coexpressing PICK1 and + Ala or 3xAla_618-620 (Fig. 9). In cells coexpressing EGFP-PICK1 and 3xAla_615-617, we observed little EGFP-PICK1 fluorescence overall, and the fluorescence observed was intracellular; however, it was not evenly distributed in the cytoplasm but colocalized with the ER-retained 3xAla_615-617 mutant (Fig. 9). The ER localization of EGFPPICK1 in the 3xAla_615-617-expressing cells was confirmed by staining against calnexin (data not shown). Moreover, we stained with an antibody against transferrin and found no colocalization with 3xAla_615-617 (data not shown). The lack of colocalization between transferrin and EGFP-PICK1 excluded the possibility that 3xAla_615-617 in the presence of PICK1 is trafficked to the surface followed by constitutive internalization to an endosomal compartment (data not shown). The data support an efficient interaction between PICK1 and 3xAla_615-617 not only in vitro but also in a cellular environment. They also show that interaction with PICK1 in itself is not sufficient to mediate surface targeting of hDAT. Rather, the data suggest the opposite scenario that hDAT could play a role in targeting PICK1 to the surface.

\section{Oligomerization properties of C-terminal mutants}

Increasing evidence suggests that DAT and related transporters form oligomers in the plasma membrane (Kilic and Rudnick, 2000; Schmid et al., 2000; Hastrup et al., 2001; Sorkina et al., 2003). For the related GABA transporter-1, assembly of the oligomeric complex is thought to be required for ER export and proper surface targeting (Scholze et al., 2002). Associated proteins could be involved in oligomerization by recruiting the transporter molecules and bringing them together or even by being parts of a scaffold that maintains the transporter molecules 


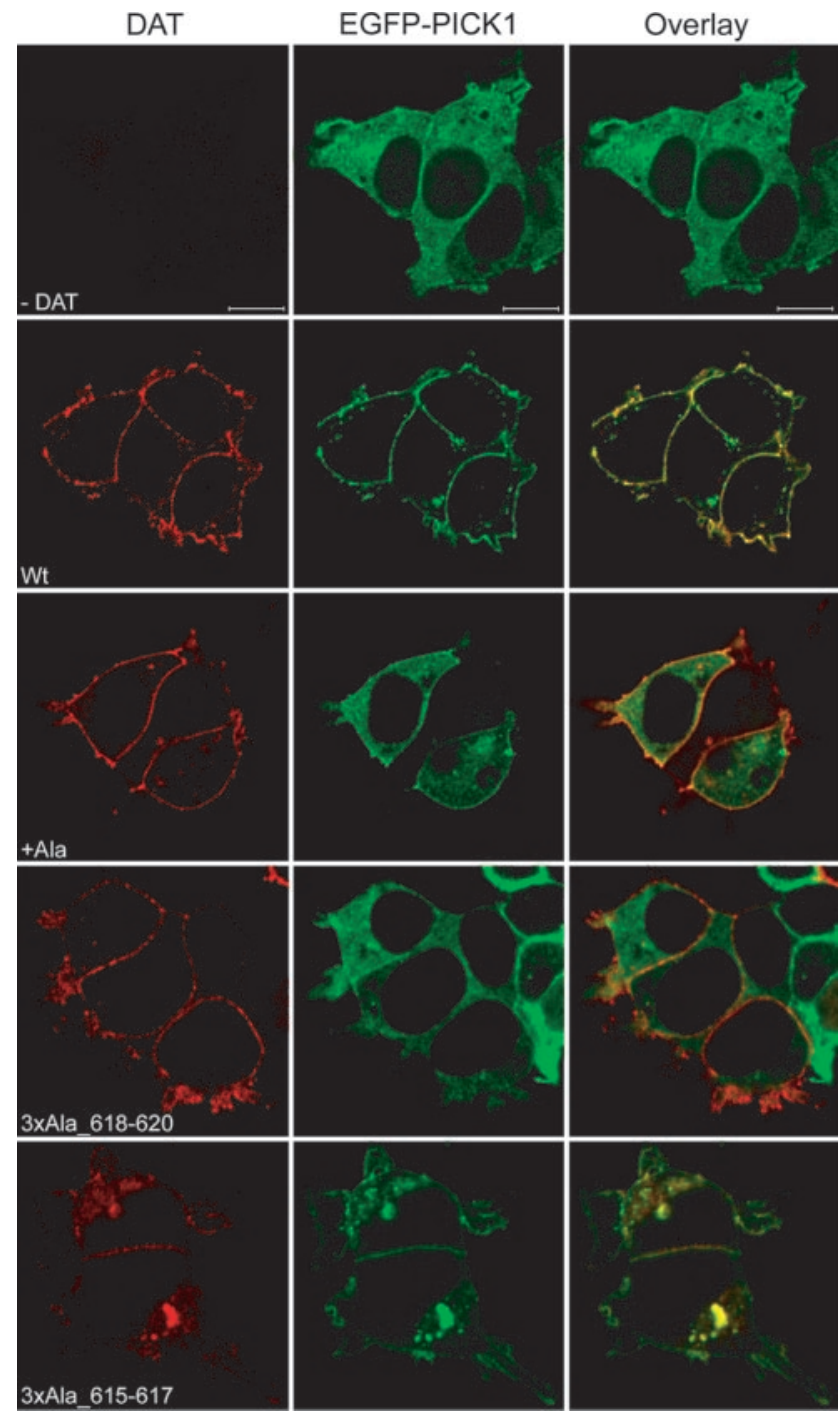

Figure 9. Immunostaining of HEK293 cells stably expressing EGFP-PICK1 alone or coexpressing WT, + Ala, 3xAla_618-620, or 3xAla_615-617 DAT and EGFP-PICK1. The cells were fixed and incubated with primary MAB369 anti-DAT antibody (1:1000), followed by secondary goat anti-rat Alexa Fluor 568 antibody and visualization by confocal fluorescence microscopy, as described in Materials and Methods. The anti-DAT (red) is shown on the left, the EGFP_PICK1 (green) is in the middle, and the overlay is on the right. Scale bar, $10 \mu \mathrm{m}$. All pictures have the same magnification.

in the oligomeric formation. Therefore, we wanted to assess oligomerization in the C-terminal DAT mutants that displayed impaired surface expression and/or impaired ability to form PDZ domain interactions. We took advantage of the recent observation that the hDAT can be symmetrically cross-linked by oxidative formation of intermolecular disulfide bridges in the presence of either $\mathrm{Cu}^{2+}$ alone or $\mathrm{CuP}$ (Hastrup et al., 2001; Hastrup and Javitch, 2003). In the presence of CuP, the transporter can be cross-linked into a dimer via a symmetrical disulfide bridge involving Cys306 at the extracellular end of transmembrane domain (TM) 6 in adjacent transporter molecules. In the presence of $\mathrm{Cu}^{2+}$ alone, symmetrical disulfide bridges can be formed involving both Cys306 and Cys 243 in adjacent transporter molecules, resulting in formation of a tetrameric structure (Hastrup et al., 2001; Hastrup and Javitch, 2003). Note that the inability of $\mathrm{CuP}$ to catalyze cross-linking of Cys 243 is most likely attributable to impaired access of $\mathrm{CuP}$ to this position deep in TM4 (Hastrup et al., 2001; Hastrup and Javitch, 2003).
A

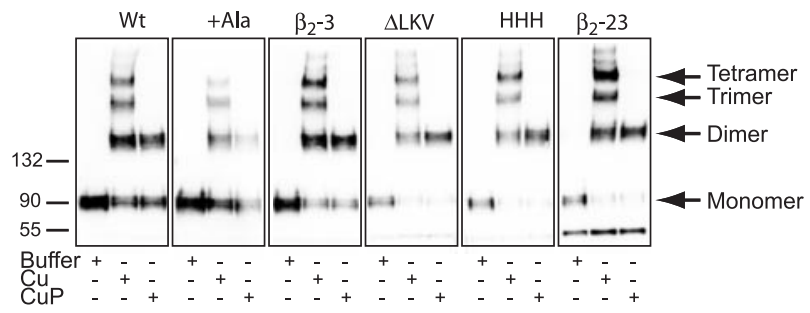

B
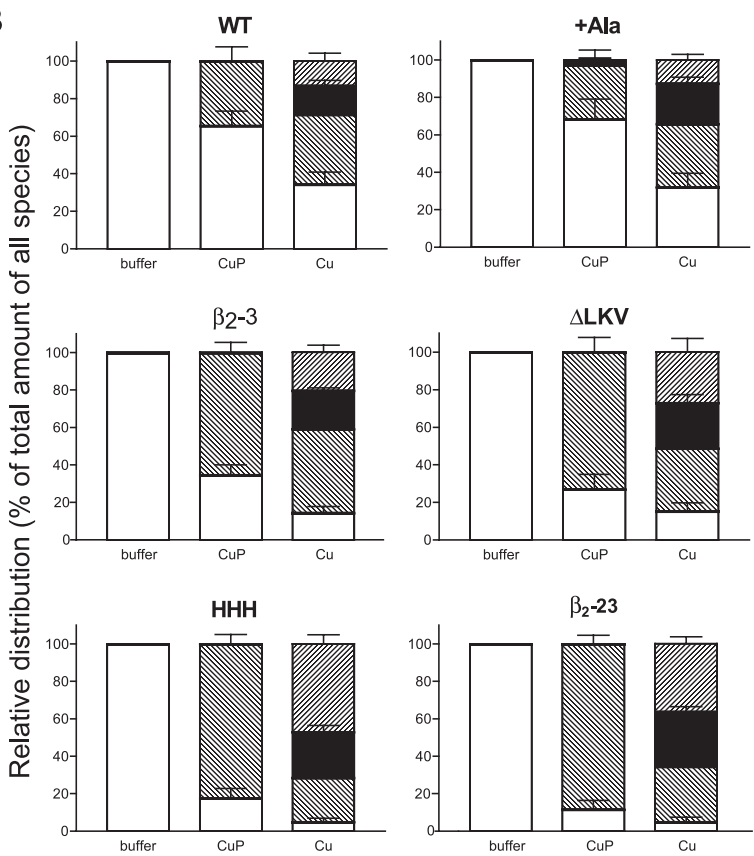

$\square$ monomer $\square$ dimer
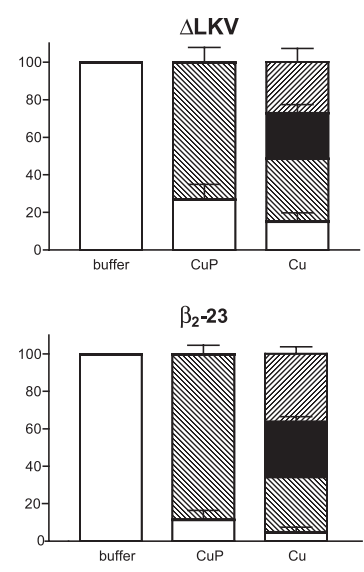

trimer Wustetramer

Figure 10. C-terminal mutations do not affect oligomerization as assessed by disulfidemediated cross-linking using Cu or CuP. A, Cross-linking of WT and indicated C-terminal mutations with Cu or CuP. After cross-linking, total cellular protein from stably transfected HEK293 cells was analyzed by SDS-PAGE, followed by immunoblotting using the M2 anti-FLAG antibody, as described in Materials and Methods. In the presence of CuP, the transporter can be cross-linked into a dimer via formation of a symmetrical disulfide bridge involving Cys306 in adjacent transporter molecules (Hastrup et al., 2001; Hastrup and Javitch, 2003). In the presence of $\mathrm{Cu}^{2+}$ alone, symmetrical disulfide bridges can be formed involving both Cys306 and Cys 243 in adjacent transporter molecules, resulting in the formation of a tetrameric structure (Hastrup et al., 2001; Hastrup and Javitch, 2003). The monomeric, dimeric, trimeric, and tetrameric species are indicated. Note that the absolute band intensities cannot be compared between the different mutants because the same amount of protein was not applied to the gels, and different exposure times have been used. B, Calculated ratios of monomer versus dimer, trimer, and tetramer. For each construct, the amount of each species (monomer, dimer, trimer, and tetramer) was quantitated by densitometry analysis on a FluorChem 8000 (Alpha Innotech, San Leandro, (A), and its relative abundance was calculated. Data are expressed as percentage of the total amount of all species observed for each individual construct (means \pm SE of 3 experiments).

In agreement with previously published data (Hastrup et al., 2001; Hastrup and Javitch, 2003), CuP treatment of WT resulted in the occurrence of a band corresponding in size to a dimer of hDAT (Fig. 10A). In the presence of $\mathrm{Cu}^{2+}$, two additional higher-order bands appeared, one corresponding in size to a trimer and one corresponding in size to a tetramer of hDAT (Fig. 10A) (Hastrup et al., 2001; Hastrup and Javitch, 2003). As illustrated in Figure $10 B$ by densitometry analysis of the Western blots, $\sim 35 \%$ of the WT migrated as a dimer during treatment with $\mathrm{CuP}$. During exposure to $\mathrm{Cu}^{2+}$, the fraction of dimer was approximately the same, but, in addition, we observed $5-10 \%$ of 
trimer and tetramer (Fig. 10B). These higher-order bands (dimer, trimer, and tetramer) were also observed with the intracellularly retained mutants $\left(\Delta \mathrm{LKV}, \mathrm{HHH}\right.$, and $\left.\beta_{2}-23\right)$, the nonPDZ domain-binding mutant + Ala, and the $\beta_{2}-3$ mutant with the type 1 PDZ-binding sequence SLL (Fig. 10A). This suggests that an intact extreme $\mathrm{C}$ terminus is not required for oligomerization of hDAT. In fact, the ratio between apparent oligomeric transporter and monomer was enhanced for the mutants displaying impaired surface targeting $\left(\Delta \mathrm{LKV}, \mathrm{HHH}\right.$, and $\left.\beta_{2}-23\right)$, as well as for $\beta_{2}-3$ (Fig. $10 B$ ). The cross-linking observed and analyzed above involves the fraction of these mutants that was maturely glycosylated; we did not find evidence that the immaturely glycosylated form of the mutants could be cross-linked, consistent with its absence from the cell surface. Thus, although we cannot rule out the possibility that the mutations that disrupt cellsurface expression might do so in part by destabilizing the formation of oligomers in the ER, the mutations clearly do not prevent normal oligomerization of the transporter that does make it to the cell surface.

\section{Discussion}

We explored the role of the $\mathrm{C}$ terminus of the hDAT for its ER export, maturation, and surface targeting. C-terminal truncations have been shown previously to display impaired surface expression (Torres et al., 2001, 2003), and this impairment was inferred to result from the loss of a critical interaction of the extreme $\mathrm{C}$ terminus with PDZ domain proteins (Torres et al., 2001, 2003). By using a mutagenesis strategy involving several types of substitutions, including alanine substitutions, histidine substitutions, and chimeric substitutions, we identified discrete epitopes in the distal hDAT C terminus that are essential for maturation and targeting of the hDAT. In contrast, we found that interactions between the C-terminal PDZ-binding sequence (LKV) and PDZ domain proteins such as PICK1 are neither necessary nor sufficient for efficient surface targeting.

To reach this conclusion, we took advantage of the well defined structural requirements for PDZ domain interactions (Sheng and Sala, 2001; Hung and Sheng, 2002) and generated mutants in the extreme $\mathrm{C}$ terminus of the hDAT that could either alter the putative PDZ-binding specificity (from type 2 to type 1 ), such as the LKV to SLL substitution $\left(\beta_{2}-3\right)$, or selectively disrupt

PDZ interactions, such as the + Ala mutation (resulting in a KVA termination sequence). Pull-down experiments using C-terminal fusion proteins of hDAT showed that neither SLL $\left(\beta_{2}-3\right)$ nor + Ala could interact with the PDZ domain of PICK1, a PDZ domain protein known to interact with hDAT (Fig. 8). Nevertheless, both the SLL $\left(\beta_{2}-3\right)$ and + Ala mutations matured properly and were efficiently targeted to the cell surface, as evidenced by surface biotinylation experiments (Fig. 3) and supported by immunofluorescence microscopy (Figs. 2, 4, respectively). Immunofluorescence studies of differentiated N2A cells also showed efficient targeting of both SLL $\left(\beta_{2}-3\right)$ and + Ala into sprouting neurites as well as both mutants displayed a cluster-like expression pattern similar to what we observed for the WT hDAT (Fig. 7).

Because PDZ domain interactions appeared not to be required for maturation and targeting of the hDAT, we attempted to define more precisely the structural epitopes in the $\mathrm{C}$ terminus important for these events. Progressive substitution of the hDAT from the $\mathrm{C}$ terminus with the corresponding amino acid sequence from the $\beta_{2}$-adrenergic receptor (beyond the terminal SLL sequence) as well as triple-alanine scanning of the C terminus showed that structural elements $\mathrm{N}$-terminal to the three last C-terminal residues, i.e., at least a stretch of residues from position 612-617, were very important for functional expression of the hDAT (Figs. 5-7; Tables 1, 2). The triple-alanine scan suggested that residues 615-617 (RHW) are more critical than the last three residues $(618-620$; LKV). Thus, hDAT was still relatively efficiently inserted into the plasma membrane and into sprouting neurites of differentiated $\mathrm{N} 2 \mathrm{~A}$ cells when residues 618-620 were substituted (3xAla_618-620), but the substitution of 615-617 (3xAla_615-617) led to retention of the transporter in the ER (Figs. 6, 7) and virtually no functional expression. Thus, 3xAla_615-617, which is capable of forming PDZ domain interactions with PICK1 as assessed in both pull-down experiments and living cells (Figs. 8, 9), displayed seriously impaired plasma membrane targeting, whereas 3xAla_618-620, which is incapable of forming PDZ domain interactions with PICK1, was surface targeted far more efficiently (Fig. 6, 7, 9),

The present mutations were tested in both HEK293 cells and neuronally derived N2A cells. Overall, a similar pattern was observed in both cell lines for the different mutations, consistent with an important role of the $\mathrm{C}$ terminus for surface expression also in the natural neuronal environment of the transporter. $\mathrm{Cu}$ riously, the effects of the mutations were somewhat greater in the N2A cells compared with the HEK293 cells (compare Tables 1,2). In agreement with this, C-terminal truncation mutants in the homologous NET have been shown recently to display impairment of maturation and surface targeting dependent on the cellular context (Bauman and Blakely, 2002). Thus, differences in the protein synthesis and maturation machinery between different cell types can markedly influence functional transporter expression at the cell surface.

Our data suggest that the hDAT C terminus plays a key role for ER export, maturation, and surface targeting of the transporter molecule, independent of PDZ domain interactions. We cannot differentiate whether the $\mathrm{C}$ terminus of DAT plays this role by itself or whether these processes require that hDAT interact with yet unknown intracellular proteins that recognize residues near the extreme $\mathrm{C}$ terminus in a non-PDZ domain-dependent manner (and thereby tolerating the + Ala and + Tyr mutations). Such interactions might occur very early in the synthesis pathway and ensure the proper folding, ER export, and targeting. There are several examples of proteins with such functions, including the so-called RAMP (receptor activity-modifying protein) proteins, which must associate with the G-protein-coupled calcitonin receptor-like receptor for this receptor to escape the ER (McLatchie et al., 1998). PDZ domain proteins can also serve such a function, i.e., syntenin must associate with the membraneanchored growth factor proTGF- $\alpha$ early in the secretory pathway to allow normal trafficking of this protein to the cell surface (Fernandez-Larrea et al., 1999).

A potential function of a protein interacting with the residues near the extreme $\mathrm{C}$ terminus of hDAT could be to shield a C-terminal ER retention signal. Such a scenario has been reported for the NMDA receptor NR1 subunit (Standley et al., 2000). However, if a retention signal was situated within the last $23 \mathrm{C}$-terminal residues of hDAT, we would have expected that intracellular retention of the $\Delta \mathrm{LKV}$ mutant could be overcome by replacing the $23 \mathrm{C}$-terminal residues of hDAT with those of the $\beta_{2}$ adrenergic receptor $\left(\beta_{2}-23\right)$, but this was not the case (Figs. $2 B$, $3 A, 5,7)$. We also found no evidence that binding of a protein to the extreme $\mathrm{C}$ terminus of hDAT could release the effect of a retention signal positioned in the $\mathrm{N}$ terminus, as demonstrated recently for 14-3-3 binding to the $\mathrm{C}$ terminus of $\mathrm{KCNK} 3$ potas- 
sium channels (O'Kelly et al., 2002). Thus, deletion of the $\mathrm{N}$-terminal 58 amino acids (N-term $\Delta 1-58$, a mutant that by itself targets to the cell surface) did not cause any signs of reversal of the $\Delta \mathrm{LKV}$ phenotype, despite the absence of the $\mathrm{N}$ terminus (data not shown).

It could furthermore be considered that an intact $\mathrm{C}$ terminus is a requirement for proper oligomerization of the transporter, and thus surface expression, but the cross-linking experiments shown in Figure 10 provide clear evidence that the mutants displaying impaired surface targeting did not lose their ability to form stable oligomers. In agreement with this observation, previous experiments with C-terminal truncations of the hDAT suggested that the $\mathrm{C}$ terminus is not required for oligomerization because coexpression of C-terminal truncation with WT hDAT resulted in partial retention of the WT protein inside the cell, seemingly attributable to oligomerization of the WT with the mutant (Torres et al., 2003).

Torres et al. (2001) described recently an interaction between the C-terminal PDZ-binding sequence of hDAT and the PDZ domain-containing protein PICK1. This protein was originally identified as a protein that interacts with activated PKC (Staudinger et al., 1995, 1997), but now additional interaction partners have been identified for PICK1, including several receptors, ion channels, and other transporters (Wyszynski et al., 1999; Xia et al., 1999; Dev et al., 2000; Lin et al., 2001; Baron et al., 2002; Duggan et al., 2002; Hirbec et al., 2002, 2003). For DAT, it was proposed that interaction with PICK1 was important for proper targeting and surface clustering of the transporter protein because overexpression of PICK1 together with the hDAT in HEK293 cells resulted in enhanced surface expression and a cluster-like expression pattern (Torres et al., 2001). The present data confirm that hDAT can interact efficiently with PICK1, but they also demonstrate that the interaction with PICK1 or a related protein is not a prerequisite for maturation, surface targeting, or expression in sprouting neurites in a differentiated neuronally derived cell line. It is important to note, however, that PICK1 might still play a modulatory role in vivo for targeting of hDAT to a specific microdomain in dopaminergic neurons, and/or it might regulate the distribution between a pool of intracellular transporters and transporters on the surface (Torres et al., 2001).

It is interesting, nonetheless, to consider other functional consequences of the PICK1 interaction. For example, the hDAT is known to be N-terminally phosphorylated in response to activation of PKC by phorbol esters or coexpressed G-protein-coupled receptors (Granas et al., 2003). Because PICK1 not only can bind PKC $\alpha$ (Staudinger et al., 1995, 1997) but can also oligomerize via its coiled-coil domain (Boudin et al., 2000), it could be envisioned that PICK1 serves to target activated PKC $\alpha$ to the hDAT, a role of PICK1 established recently for the kainate-type glutamate receptors (Hirbec et al., 2003) and the acid-sensing ion channel ASIC2a (Baron et al., 2002). Finally, it is important to note that likely other PDZ domain proteins can interact with the hDAT C terminus with as yet undefined functional consequences.

\section{References}

Amara SG, Kuhar MJ (1993) Neurotransmitter transporters: recent progress. Annu Rev Neurosci 16:73-93.

Barlowe C (2003) Signals for COPII-dependent export from the ER: what's the ticket out? Trends Cell Biol 13:295-300.

Baron A, Deval E, Salinas M, Lingueglia E, Voilley N, Lazdunski M (2002) Protein kinase $\mathrm{C}$ stimulates the acid-sensing ion channel ASIC2a via the PDZ domain-containing protein PICK1. J Biol Chem 277:50463-50468.

Bauman PA, Blakely RD (2002) Determinants within the C-terminus of the human norepinephrine transporter dictate transporter trafficking, stability, and activity. Arch Biochem Biophys 404:80-91.

Blakely RD, Bauman AL (2000) Biogenic amine transporters: regulation in flux. Curr Opin Neurobiol 10:328-336.

Boudin H, Doan A, Xia J, Shigemoto R, Huganir RL, Worley P, Craig AM (2000) Presynaptic clustering of mGluR7a requires the PICK1 PDZ domain binding site. Neuron 28:485-497.

Cao TT, Deacon HW, Reczek D, Bretscher A, von Zastrow M (1999) A kinase-regulated PDZ-domain interaction controls endocytic sorting of the beta2-adrenergic receptor. Nature 401:286-290.

Chen N, Reith ME (2000) Structure and function of the dopamine transporter. Eur J Pharmacol 405:329-339.

Daniels GM, Amara SG (1999) Regulated trafficking of the human dopamine transporter: clathrin-mediated internalization and lysosomal degradation in response to phorbol esters. J Biol Chem 274:35794-35801.

Dev KK, Nakajima Y, Kitano J, Braithwaite SP, Henley JM, Nakanishi S (2000) PICK1 interacts with and regulates PKC phosphorylation of mGLUR7. J Neurosci 20:7252-7257.

Duggan A, Garcia-Anoveros J, Corey DP (2002) The PDZ domain protein PICK1 and the sodium channel $\mathrm{BNaCl}$ interact and localize at mechanosensory terminals of dorsal root ganglion neurons and dendrites of central neurons. J Biol Chem 277:5203-5208.

Ellgaard L, Helenius A (2003) Quality control in the endoplasmic reticulum. Nat Rev Mol Cell Biol 4:181-191.

Ellgaard L, Molinari M, Helenius A (1999) Setting the standards: quality control in the secretory pathway. Science 286:1882-1888.

Fernandez-Larrea J, Merlos-Suarez A, Urena JM, Baselga J, Arribas J (1999) A role for a PDZ protein in the early secretory pathway for the targeting of proTGF-alpha to the cell surface. Mol Cell 3:423-433.

Gage RM, Kim KA, Cao TT, von Zastrow M (2001) A transplantable sorting signal that is sufficient to mediate rapid recycling of $\mathrm{G}$ protein-coupled receptors. J Biol Chem 276:44712-44720.

Granas C, Ferrer J, Loland CJ, Javitch JA, Gether U (2003) N-terminal truncation of the dopamine transporter abolishes phorbol ester- and substance $\mathrm{P}$ receptor-stimulated phosphorylation without impairing transporter internalization. J Biol Chem 278:4990-5000.

Hall RA, Ostedgaard LS, Premont RT, Blitzer JT, Rahman N, Welsh MJ, Lefkowitz RJ (1998) A C-terminal motif found in the beta2-adrenergic receptor, P2Y1 receptor and cystic fibrosis transmembrane conductance regulator determines binding to the $\mathrm{Na}^{+} / \mathrm{H}^{+}$exchanger regulatory factor family of PDZ proteins. Proc Natl Acad Sci USA 95:8496-8501.

Hastrup H, Karlin A, Javitch JA (2001) Symmetrical dimer of the human dopamine transporter revealed by cross-linking Cys-306 at the extracellular end of the sixth transmembrane segment. Proc Natl Acad Sci USA 98:10055-10060.

Hastrup H, Sen H, Javitch JA (2003) The human dopamine transporter forms a tetramer in the plasma membrane: cross-linking of a cysteine in the fourth transmembrane segment is sensitive to cocaine analogs. J Biol Chem 278:45045-45048.

Hirbec H, Perestenko O, Nishimune A, Meyer G, Nakanishi S, Henley JM, Dev KK (2002) The PDZ proteins PICK1, GRIP, and syntenin bind multiple glutamate receptor subtypes. Analysis of PDZ binding motifs. J Biol Chem 277:15221-15224.

Hirbec H, Francis JC, Lauri SE, Braithwaite SP, Coussen F, Mulle C, Dev KK, Coutinho V, Meyer G, Isaac JT, Collingridge GL, Henley JM, Couthino V (2003) Rapid and differential regulation of AMPA and kainate receptors at hippocampal mossy fibre synapses by PICK1 and GRIP. Neuron 37:625-638.

Hung AY, Sheng M (2002) PDZ domains: structural modules for protein complex assembly. J Biol Chem 277:5699-5702.

Kilic F, Rudnick G (2000) Oligomerization of serotonin transporter and its functional consequences. Proc Natl Acad Sci USA 97:3106-3111.

Lin WJ, Chang YF, Wang WL, Huang CY (2001) Mitogen-stimulated TIS21 protein interacts with a protein-kinase-C alpha-binding protein rPICK1. Biochem J 354:635-643.

Loder MK, Melikian HE (2003) The dopamine transporter constitutively internalizes and recycles in a protein kinase C-regulated manner in stably transfected PC12 cell lines. J Biol Chem 278:22168-22174.

McLatchie LM, Fraser NJ, Main MJ, Wise A, Brown J, Thompson N, Solari R, Lee MG, Foord SM (1998) RAMPs regulate the transport and ligand specificity of the calcitonin-receptor-like receptor. Nature 393:333-339.

Muth TR, Ahn J, Caplan MJ (1998) Identification of sorting determinants in 
the C-terminal cytoplasmic tails of the gamma-aminobutyric acid transporters GAT-2 and GAT-3. J Biol Chem 273:25616-25627.

Norregaard L, Gether U (2001) The monoamine neurotransmitter transporters: structure, conformational changes and molecular gating. Curr Opin Drug Discov Devel 4:591-601.

O’Kelly I, Butler MH, Zilberberg N, Goldstein SA (2002) Forward transport. 14-3-3 binding overcomes retention in endoplasmic reticulum by dibasic signals. Cell 111:577-588.

Perego C, Vanoni C, Villa A, Longhi R, Kaech SM, Frohli E, Hajnal A, Kim SK, Pietrini G (1999) PDZ-mediated interactions retain the epithelial GABA transporter on the basolateral surface of polarized epithelial cells. EMBO J 18:2384-2393.

Rees S, Coote J, Stables J, Goodson S, Harris S, Lee MG (1996) Bicistronic vector for the creation of stable mammalian cell lines that predisposes all antibiotic-resistant cells to express recombinant protein. Biotechniques 20:102-110

Robinson MB (2002) Regulated trafficking of neurotransmitter transporters: common notes but different melodies. J Neurochem 80:1-11.

Saunders C, Ferrer JV, Shi L, Chen J, Merrill G, Lamb ME, Leeb-Lundberg LM, Carvelli L, Javitch JA, Galli A (2000) Amphetamine-induced loss of human dopamine transporter activity: an internalization-dependent and cocaine-sensitive mechanism. Proc Natl Acad Sci USA 97:6850-6855.

Schmid JA, Scholze P, Kudlacek O, Freissmuth M, Singer EA, Sitte HH (2000) Oligomerization of the human serotonin transporter and of the rat GABA transporter 1 visualized by fluorescence resonance energy transfer microscopy in living cells. J Biol Chem 276:3805-3810.

Scholze P, Freissmuth M, Sitte HH (2002) Mutations within an intramembrane leucine heptad repeat disrupt oligomer formation of the rat GABA transporter 1. J Biol Chem 277:43682-43690.

Sheng M, Sala C (2001) PDZ domains and the organization of supramolecular complexes. Annu Rev Neurosci 24:1-29.

Sorkina T, Doolen S, Galperin E, Zahniser NR, Sorkin A (2003) Oligomer- ization of dopamine transporters visualized in living cells by fluorescence resonance energy transfer microscopy. J Biol Chem 278:28274-28283.

Standley S, Roche KW, McCallum J, Sans N, Wenthold RJ (2000) PDZ domain suppression of an ER retention signal in NMDA receptor NR1 splice variants. Neuron 28:887-898.

Staudinger J, Zhou J, Burgess R, Elledge SJ, Olson EN (1995) PICK1: a perinuclear binding protein and substrate for protein kinase $\mathrm{C}$ isolated by the yeast two-hybrid system. J Cell Biol 128:263-271.

Staudinger J, Lu J, Olson EN (1997) Specific interaction of the PDZ domain protein PICK1 with the $\mathrm{COOH}$ terminus of protein kinase $\mathrm{C}$-alpha. J Biol Chem 272:32019-32024

Torres GE, Yao WD, Mohn AR, Quan H, Kim KM, Levey AI, Staudinger J, Caron MG (2001) Functional interaction between monoamine plasma membrane transporters and the synaptic PDZ domain-containing protein PICK1. Neuron 30:121-134.

Torres GE, Carneiro A, Seamans K, Fiorentini C, Sweeney A, Yao WD, Caron MG (2003) Oligomerization and trafficking of the human dopamine transporter. Mutational analysis identifies critical domains important for the functional expression of the transporter. J Biol Chem 278:2731-2739.

Vashist S, Kim W, Belden WJ, Spear ED, Barlowe C, Ng DT (2001) Distinct retrieval and retention mechanisms are required for the quality control of endoplasmic reticulum protein folding. J Cell Biol 155:355-368.

Wyszynski M, Valtschanoff JG, Naisbitt S, Dunah AW, Kim E, Standaert DG, Weinberg R, Sheng M (1999) Association of AMPA receptors with a subset of glutamate receptor-interacting protein in vivo. J Neurosci 19:6528-6537.

Xia J, Zhang X, Staudinger J, Huganir RL (1999) Clustering of AMPA receptors by the synaptic PDZ domain-containing protein PICK1. Neuron 22:179-187.

Zahniser NR, Doolen S (2001) Chronic and acute regulation of $\mathrm{Na}^{+} / \mathrm{Cl}^{-}$. dependent neurotransmitter transporters: drugs, substrates, presynaptic receptors, and signaling systems. Pharmacol Ther 92:21-55. 